\title{
Fractal Properties of Various Clay Minerals Obtained from SEM Images
}

\author{
Naser Golsanami $\mathbb{D}^{1,2}$ Shanilka Gimhan Fernando $\mathbb{D}^{2},{ }^{2}$ Madusanka Nirosh Jayasuriya $\mathbb{D}^{\mathbb{D}}{ }^{2}$ \\ Weichao Yan $\mathbb{D}^{3}{ }^{3}$ Huaimin Dong $\mathbb{D}^{3}{ }^{3}$ Likai Cui $\mathbb{D}^{4},{ }^{4}$ Xu Dong $\mathbb{D}^{5},{ }^{5}$ and Ehsan Barzgar $\mathbb{D}^{6}$ \\ ${ }^{1}$ State Key Laboratory of Mining Disaster Prevention and Control, Shandong University of Science and Technology, \\ Qingdao 266590, China \\ ${ }^{2}$ College of Energy and Mining Engineering, Shandong University of Science and Technology, Qingdao 266590, China \\ ${ }^{3}$ Department of Well Logging, School of Geosciences, China University of Petroleum (Huadong), Qingdao 266580, China \\ ${ }^{4}$ Institute of Unconventional Oil and Gas, Northeast Petroleum University, Daqing 163318, China \\ ${ }^{5}$ Key Laboratory of Continental Shale Hydrocarbon Accumulation and Efficient Development, Northeast Petroleum University, \\ Daqing 163318, China \\ ${ }^{6}$ State Key Laboratory of Petroleum Resources and Prospecting and Unconventional Petroleum Research Institute, China University \\ of Petroleum, Beijing 102249, China
}

Correspondence should be addressed to Naser Golsanami; golsanami_naser@yahoo.com and Shanilka Gimhan Fernando; shanilkagimhan@gmail.com

Received 12 February 2021; Revised 6 April 2021; Accepted 7 June 2021; Published 19 June 2021

Academic Editor: Qingquan Liu

Copyright (c) 2021 Naser Golsanami et al. This is an open access article distributed under the Creative Commons Attribution License, which permits unrestricted use, distribution, and reproduction in any medium, provided the original work is properly cited.

\begin{abstract}
Clay minerals significantly alter the pore size distribution (PSD) of the gas hydrate-bearing sediments and sandstone reservoir rock by adding an intense amount of micropores to the existing intragranular pore space. Therefore, in the present study, the internal pore space of various clay groups is investigated by manually segmenting Scanning Electron Microscopy (SEM) images. We focused on kaolinite, smectite, chlorite, and dissolution holes and characterized their specific pore space using fractal geometry theory and parameters such as pore count, pore size distribution, area, perimeter, circularity, and density. Herein, the fractal properties of different clay groups and dissolution holes were extracted using the box counting technique and were introduced for each group. It was observed that the presence of clays complicates the original PSD of the reservoir by adding about 1.3161.30 pores $/ 100 \mu \mathrm{m}^{2}$ with sizes in the range of $0.003-87.69 \mu \mathrm{m}^{2}$. Meanwhile, dissolution holes complicate the pore space by adding 4.88-8.17 extra pores/100 $\mu \mathrm{m}^{2}$ with sizes in the range of $0.06-119.75 \mu \mathrm{m}^{2}$. The fractal dimension $(D)$ and lacunarity $(L)$ values of the clays' internal pore structure fell in the ranges of 1.51-1.85 and 0.18-0.99, respectively. Likewise, $D$ and $L$ of the dissolution holes were in the ranges of, respectively, 1.63-1.65 and 0.56-0.62. The obtained results of the present study lay the foundation for developing improved fractal models of the reservoir properties which would help to better understand the fluid flow, irreducible fluid saturation, and capillary pressure. These issues are of significant importance for reservoir quality and calculating the accurate amount of producible oil and gas.
\end{abstract}

\section{Introduction}

Clay minerals are found in most kinds of conventional and unconventional oil and gas reservoirs. These minerals typically fall into five major groups which include kaolinite, chlorite, illite, smectite (montmorillonite), and illite-smectite mixed-layer clays. In the oil and gas industry, clay minerals could play a very positive role as the colloidal base of almost all water-based drilling muds or as the regulator of the $\mathrm{pH}$ of the pore fluids [1]. Nevertheless, they bring about serious challenges from the perspective of reservoir quality. Such challenges are principally related to the wellbore instability and fluid flow in manners such as swelling of smectites, migration/dispersion of illite, kaolinite, and even smectites, 
and also the transformation of clay minerals into other mineral phases [2, 3]. Swelling of clays may occur at different stages of drilling, hydraulic fracturing, or production, which not only damages cementing quality and petrophysical logging records but also in a larger view shortens the lifetime of the borehole and causes great expenses [4]. With regard to the fluid flow, the clay-caused challenges usually include migration and concentration of clay in the pore throats, and damaging the permeability $[2,5,6]$. Therefore, understanding the detailed properties of the clay minerals in the hydrocarbon reservoir is of benefit for all drilling, well logging, and reservoir engineers.

The challenges posed by clay minerals have been discussed thoroughly in the existing literature. However, one particular challenge has never been resolved. This challenge is the quantitative characterization of how the clay minerals alter the original pore size distribution (PSD) of the reservoir. That is to say, the existing studies have all studied the intragranular pore space (porosity between rock grains), but the internal pore space of the clays itself, i.e., the pores specifically inside different clay minerals, has not been characterized in detail yet. A huge number of micro- and nanopores exist within the structure of different clays because of their morphological properties. These extra pores that we call them "clay's internal pore space (CIPS)" considerably increase the capillarity and the surface-to-volume ratio of the pore, which in turn increases the amount of irreducible fluid saturation. All these phenomena alter the fluid-surface interactions such as surface relaxivity in NMR measurements and could create inaccurate estimations of porosity and permeability in reservoir engineering [7]. Therefore, it is crucial to understand their detailed pore structural characteristics for improved hydrocarbon production and also orienting EOR planning. In the present study, we focused on kaolinite, smectite, chlorite, and dissolution holes and analyzed their detailed pore structural characteristics. The characteristics that were investigated in this study included pore count, pore size distribution, perimeter, circularity, area, and density that were determined for different clay groups for the first time. Moreover, as observed in the present study, CIPS of each clay group is a fractal body by itself for which the fractal properties are much different from those of the other clays and the intragranular PSD. Therefore, we determined the fractal dimension and fractal lacunarity of these clays by implementing the box counting method. Among the existing studies, only a very limited number have focused on fractal properties of clays, which are very old and also assume clays to be self-similar fractal objects. This is an incorrect fundamental assumption since, unlike mathematical fractals, the porous medium is not exactly self-similar but is rather statistically similar. For exactly self-similar fractals, the wellknown fractal dimension log-log plot turns out to be a straight line while for statistical fractals, the points are scattered very close to the straight line [8]. Hence, to the authors' best knowledge, this is the first attempt to specifically report the detailed fractal characteristics of various types of clay minerals.

This study was conducted based on the Scanning Electron Microscopy (SEM) images. This is because SEM imag- ing is a fast and widely accessible method that provides a direct insight into the reservoir rock and provides more precise information compared to similar techniques such as nuclear magnetic resonance spectroscopy/imaging. The implemented SEM images of the present study were recorded using the core samples from the sandy conglomerate oil reservoir of the Beibuwan Basin and also the natural gas hydrate-bearing sediments (GHBS) of the Qilian Mountain permafrost of China. Natural gas hydrate is an unconventional gas resource, and it has proven to be a great substitution for fossil fuels for the future energy demand of the world as its gas resources are 10 times more than global conventional gas reserves and twice the total carbon content in all the coal, petroleum, and natural gas in the world [9]. Gas hydrates have the unique characteristics that they expand 150-170 times when they reach the surface temperature and pressure. This property indicates that one cubic foot of gas hydrates found at the subsurface may produce 150-170 cubic feet of natural gas at surface conditions $[10,11]$. However, despite the current understanding of all the sandstone and carbonate reservoirs, our knowledge of gas hydratebearing sediments is still very limited.

Regarding the characterization of clay minerals using fractal geometry, a report from 1996 compared various techniques such as small-angle X-ray scattering (SAXS), adsorption, and nuclear magnetic resonance (NMR) for determining the fractal dimensions of clay minerals [12]. Meanwhile, there have been studies examining the fractal model for virgin compression of pure clays [13] and the fractal structure of pores in clay soil [14]. In recent years, there has been a growing interest in the application of the fractal geometry theory to study hydrocarbon-bearing rocks. Nevertheless, most of these studies have focused on characterizing the pore size distribution. Accordingly, many fractal-based expressions have been driven for transport analysis of the reservoir and to describe its petrophysical, fluid flow, and hydraulic properties. A limited number of these studies have also revised/improved the fractal-based models of, e.g., absolute and relative permeability, flow, heterogeneity, connectivity, tortuosity, and pore throat morphology under the impact of the swelling clays [15-17]. Swelling reduces the porosity and questions the reliability of those models that assume a constant unchanging pore network with a single value of the fractal dimensions at all length-time scales.

As can be understood, the issues raised in the present study have not been reported in the existing research works. The new development with regard to the presence of clay minerals in the present research is that the research results provide the detailed characteristics of various clay minerals which have not been reported previously. Once these properties are known, they could be meticulously merged into the existing fractal-based equations in petrophysical and geomechanical characterization models. As already known, in hydrocarbon reservoirs, various models of pore space permeability and connectivity, pore radius and pore throat radius distribution, flow paths and pore network tortuosity, etc. have been modeled with fractal geometry theory. In these models, the pore space is either simulated [18, 19], captured by NMR [20-24], or obtained through computed 
tomography (CT) scanning and digital rock technology [2527]. However, in most cases, a part of the microscopic pore space could not be captured by NMR or micro-CT. This is where SEM imaging has been used for improving the result and also resolving the issues of the microporous phase in CT images [28-30]. Therefore, the existing models are based more on the intragranular pores rather than the precise pore space characteristic. The results of the present study provide the quantitative systematic understanding of the extra micro/nanopores added to the intragranular pore space. Therefore, beyond the pore space characterization, the present study lays the theoretical foundation for improving the wide range of existing models by taking the clay's quantitative internal pore space into consideration. Since the various characteristics of clays are quantitatively extracted in the present study, developing and validating new models are expected to lead to more reliable reservoir characterization results. The authors believe that the obtained results of the present study could also contribute to a better understanding of clay-caused problems in hydrocarbon reservoirs. The rest of the paper is organized as follows. Section 2 introduces the study areas. Section 3 reviews the background knowledge of clay minerals and fractal geometry theory. Section 4 provides the various phenomena observed in the SEM images of clay minerals. Sections 5 and 6 deliver the obtained results and discussion, respectively. Finally, conclusions are represented in Section 7.

\section{Study Area}

The Beibuwan Basin is a Mesozoic-Cenozoic extensional basin that includes three uplifts and six subbasins. The basin, as illustrated in Figure 1(a), is located in the northern continental shelf of the South China Sea. The structural evolution of the basin is divided into an early (Eocene to Oligocene) extensional phase and a late (Miocene to recent) passive margin phase $[31,32]$. In this basin, the most significant source rock for oil and gas is the Mid-to-Upper-Eocene Liushagang Formation deposited at the peak of the lacustrine development. In this formation, the dark mudstone has got a thickness ranging from tens of meters to over $1000 \mathrm{~m}$ and contains abundant organic materials (primarily type II kerogen) [33]. In the area, the oil- and gas-bearing sags are Weizhou, Wushi, and Fushan where oil and gas explorations have been conducted more than those in the other sections $[33,34]$.

In the Scientific Drilling Project of Gas Hydrates in the Qilian Mountains, the Sanlutian coalfield located in the Juhugeng mine area is the major studied area (Figure 1(b)). Muli is a Middle Jurassic formation divided into the upper and lower Muli where the lower Muli is composed of coarse sandstone and medium sandstone. The upper Muli mainly includes mudstone, siltstone, fine sandstone, and a coal seam [36]. Drilling for the gas hydrate in the Muli area started in 2008 by 12 small aperture boreholes including DK-1, DK-2, DK-3, DK-4, DK-5, DK-6, DK-7, DK-8, DK-9, DK-10, DK11, and DK-12. This operation was carried out by the China Geological Survey. Following these drillings, gas hydrate turned out to exist in seven boreholes being DK-1, DK-2,
DK-3, DK-7, DK-8, DK-9, and DK-12 [35, 36, 39]. The operation was continued till 2012 which was followed by the operation of Qinghai No. 105 Coal Geological Exploration Team for drilling 14 more boreholes during 2013 and 2014. These boreholes were DK2-25, DK2-26, DK4-23, DK4-24, DK5-22, DK6-21, DK7-20, DK8-19, DK10-16, DK10-17, DK10-18, DK11-14, DK12-13, and DK13-11. Herein, gas hydrates were discovered in four boreholes being DK8-19, DK11-14, DK12-13, and DK13-11 [37, 40, 41]. The gas hydrate in the area is generally produced at the depth of 130-400 m. SEM images obtained from the area indicated that the clay exists within the sediments in two forms of dispersed clays and laminated clay [40].

\section{Background}

3.1. Typical Groups of Clay Minerals in Hydrocarbon Reservoirs. Clays are composed of a heterogeneous mixture of finely divided minerals, such as quartz, feldspars, calcite, and pyrites [4]. The Joint Nomenclature Committee (JNC) of AIPEA and the Clay Minerals Society define clay as a naturally occurring material composed primarily of fine-grained minerals, which is generally plastic at appropriate water contents and will harden when dried or fired $[4,42]$. The constituting chemical elements of the clay minerals are as follows $[3,4,43]$ :

(i) Kaolinite: $\mathrm{Al}_{4}\left[\mathrm{Si}_{4} \mathrm{O}_{10}\right](\mathrm{OH})_{8}$

(ii) Chlorite: $(\mathrm{Mg}, \mathrm{Al}, \mathrm{Fe})_{12}\left[(\mathrm{Si}, \mathrm{Al})_{8} \mathrm{O}_{20}\right](\mathrm{OH})_{16}$

(iii) Illite: (K1-1,5Al4[Si7-6,5Al1-1,50 $\left.\left.\mathrm{O}_{20}\right](\mathrm{OH})_{4}\right)$

(iv) Smectite (montmorillonite): $\quad(1 / 2 \mathrm{Ca}, \mathrm{Na})_{0,7}$ $(\mathrm{Al}, \mathrm{Mg}, \mathrm{Fe})_{4}\left[(\mathrm{Si}, \mathrm{Al})_{8} \mathrm{O}_{20}\right] \cdot n \mathrm{H}_{2} \mathrm{O}$

(v) Mixed layer: illite-smectite and chlorite-smectite

(vi) Vermiculite: $\mathrm{Mg}_{3}\left(\mathrm{Si}_{3} \mathrm{Al}\right) \mathrm{O}_{10}(\mathrm{OH})_{2} \mathrm{Mg}_{(\text {exch }) .5}\left(\mathrm{H}_{2} \mathrm{O}\right)_{4}$, where $\mathrm{Mg}_{(\text {exch })}$ is exchangeable $\mathrm{Mg}$. Some researchers consider vermiculite as a subgroup of the smectite (montmorillonite) group

(vii) Sepiolite: $\mathrm{Mg}_{8} \mathrm{Si}_{12} \mathrm{O}_{30} \mathrm{OH}_{4}\left(\mathrm{OH}_{2}\right)_{4} \cdot X\left[\mathrm{M}^{2+}\left(\mathrm{H}_{2} \mathrm{O}\right)_{8}\right]$, and palygorskite: $\mathrm{MgAlS}_{8} \mathrm{O}_{20} \mathrm{OH}_{3}\left(\mathrm{OH}_{2}\right)_{4} \cdot \mathrm{X}$ $\left[\mathrm{M}^{2+}\left(\mathrm{H}_{2} \mathrm{O}\right)_{4}\right]$ where $\mathrm{M}^{2+}$ is cations in the tube "tunnels" and $X$ is octahedral sites in sepiolite which may contain $\mathrm{Al}, \mathrm{Fe}, \mathrm{Mn}$, or $\mathrm{Ni}$, while in palygorskite, $\mathrm{Na}, \mathrm{Fe}$, and Mn may be present

3.2. Fractal Dimension. The fractal geometry theory was founded in 1967 by Mandelbrot [44]. This theory could be considered the extension of the conventional Euclidean geometry. In conventional geometry, integer dimensions are used to describe $2 \mathrm{D}$ and $3 \mathrm{D}$ objects in the form of surface $=$ length $^{2}$ and volume $=$ length $^{3}$. However, in fractal geometry which is used to describe fractal objects, the dimensions are not necessarily integer values and would be noninteger or fractional. The most important property that determines whether an object is fractal or not is its "scaleinvariant self-similarity details" or simply called "self- 


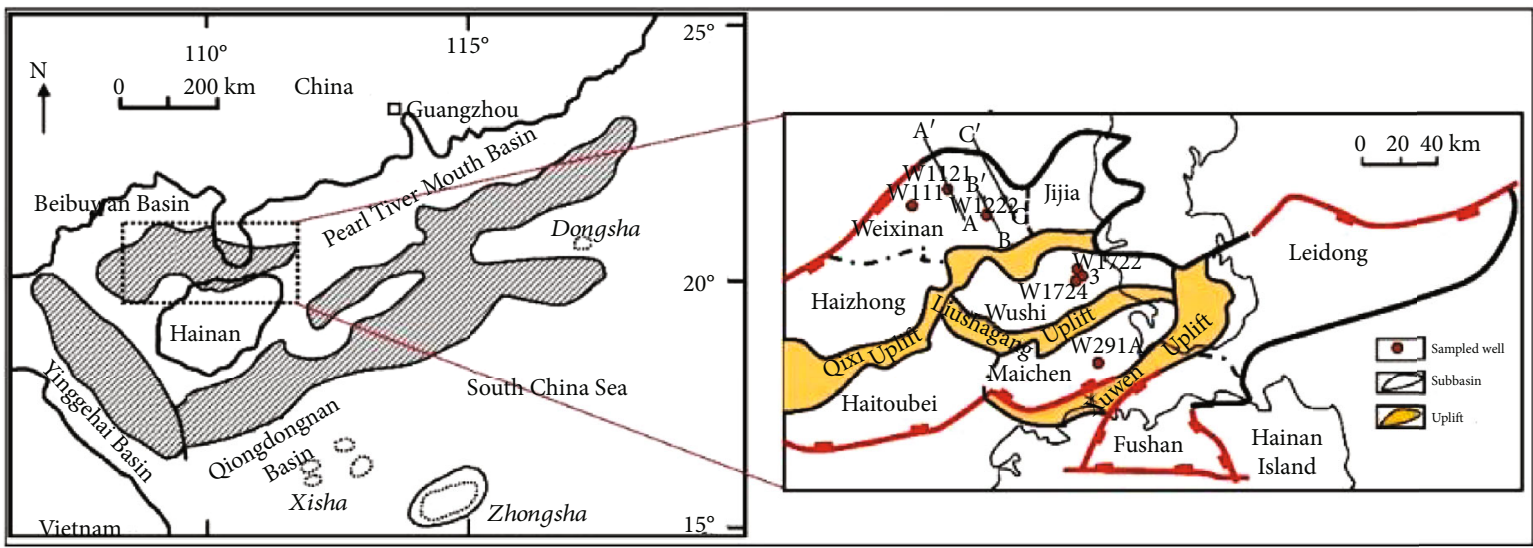

(a)
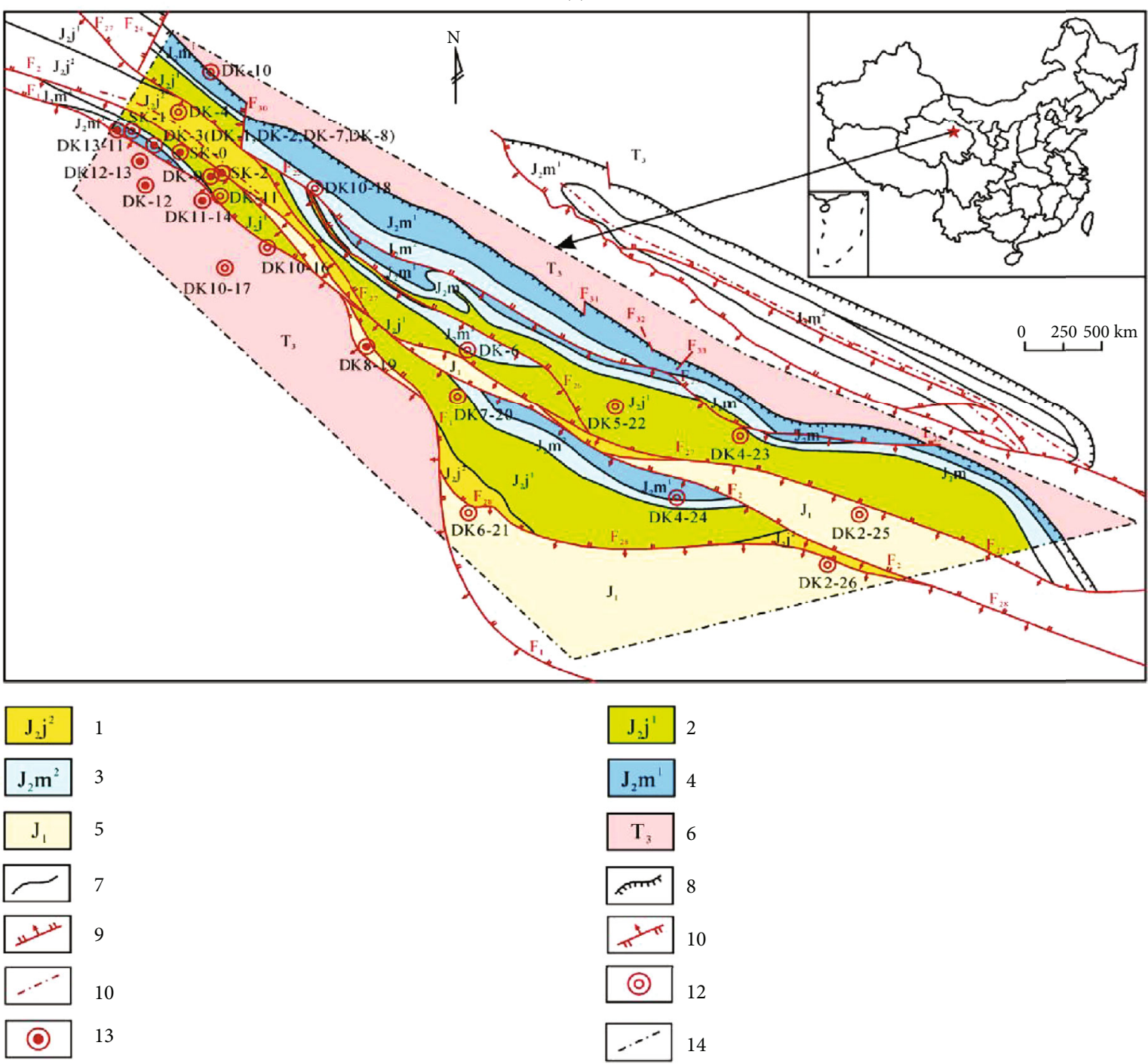

(b)

FIgURE 1: (a) Location and structural division of the Beibuwan Basin [32] and (b) geological map of the Sanlutian coalfield and location of the Scientific Drilling Project of Gas Hydrates in the Qilian Mountains [35-38]. 1: upper Jiangcang, 2: lower Jiangcang, 3: upper Muli, 4: lower Muli, 5: lower Jurassic, 6: upper Triassic, 7: concordant stratigraphic boundary, 8: discordant stratigraphic boundary, 9: normal fault, 10: reverse fault, 11: supposed fault, 12: no gas hydrate borehole, 13: gas hydrate borehole, and 14: research boundary. 
similarity." This means that a fractal object/pattern/or texture turns out to repeat itself infinitely when one inspects it closer and closer, i.e., increasing the scale, magnification, or resolution. A good description in the existing literature is that if a simple straight line is magnified, it turns out as a simple line for infinite times of magnifications, but if a fractal line is magnified, it never appears as a simple straight piece of a line [45]. Nonetheless, every fractal object has got a different level of complexity. This means that when the resolution is increased, the number of details observed for a complex fractal object would be much more than those for a simple one. To describe this complexity (or irregularity) of shape and differentiate between different objects, fractal dimension, typically denoted as $D$, has been defined. This number does not measure height, area, width, density, or frequency, but it indicates the scale-invariant complexity of the fractal object's details. $D$ is indeed a single-value number that is obtained by only a limited sample data from the fractal object [46].

3.3. Lacunarity and Succolarity. The characteristics of a fractal would not be perfectly determined by its sole fractal dimension. This implies that two fractal objects of different characteristics might have the same value of $D$. Therefore, other fractal structural parameters have been introduced as the counterparts of $D$. These parameters include lacunarity $(L)$ and succolarity. In fact, fractal objects (or fractal sets when we consider them images) have three properties which are (i) scale-invariant complexity of shape (roughness) described by fractal dimension, (ii) inhomogeneity or structural variations (texture) described by lacunarity, and (iii) percolation degree described by succolarity. Lacunarity deals with the size distribution of the holes within the fractal pattern, which is defined as the degree of translational and rotational invariance in the image $[45,46]$. In other words, if a fractal object has got large holes or gaps, it will have a high lacunarity and vice versa. Therefore, $L$ represents the gappiness or visual texture of the fractal object. Succolarity on the other hand describes the connectivity of an image/system in various directions or the degree of filaments that allow percolation through the fractal set $[47,48]$. In the context of the pore space studies of reservoir rocks, succolarity measures the ability of a fluid to permeate within the porous medium of the reservoir rock. Therefore, it is a good measure of the permeability obtained through computed tomography (CT) images or other imaging techniques. In summary, for studying the microstructure of the pore space in the rocks, fractal dimension, lacunarity, and succolarity are, respectively, used for determining the complexity, heterogeneity, and anisotropy of pore space structure [49].

3.4. Calculating Fractal Dimension and Lacunarity. The most popular approach for calculating the above-mentioned three parameters is the box counting method, fundamentals of which are represented in the published reports [46, 47]. Fractal geometry theory has been used for characterizing the pore structure of conventional and unconventional reservoir rocks $[20,50-52]$, as well as gas hydrate-bearing sediments in recent years [26, 52-56]. According to a fundamental study of Pfeifer and Avnir [57] and as reported in the later applica- tions $[58,59]$, in a fractal structure, the number of elements $N$ has got a power-law relationship with the element's length scale $r$ as

$$
N=\frac{C}{r^{D}}
$$

where $C$ is the constant of proportionality and $D$ represents the fractal dimension. On the other hand, according to Kozeny-Carman's model of rock $[60,61]$, the pore space consists of numerous capillary tubes $[62,63]$. Therefore, by assuming the pore volume corresponding to a fixed radius, i.e., $V(r)$, we have

$$
N=\frac{V(r)}{\pi r^{2} l}
$$

where $r$ indicates the radius and $l$ is the length of a capillary tube. According to the self-similarity rule as the core of the fractal geometry theory, there should be a constant ratio between the length and radius of the capillary tubes as fractal elements. Therefore, for simplicity, we assume $l=r$, after which we have $[62,63]$

$$
\begin{gathered}
V(r)=N \pi r^{3}=\frac{C}{r^{D}} \times \pi r^{3}, \\
V(r)=C \pi r^{3-D} .
\end{gathered}
$$

This way, the differential pore volume distribution would be

$$
\frac{d V(r)}{d r}=(3-D) C \pi r^{2-D}
$$

The cumulative volume of pores with radiuses less than the desired radius $r$ would be defined by integration over the pore radiuses smaller than $r$ as follows:

$$
\begin{gathered}
V(<r)=\int_{r_{\min }}^{r}(3-D) C \pi r^{2-D} d r, \\
V(<r)=C \pi\left(r^{3-D}-r_{\min }^{3-D}\right) .
\end{gathered}
$$

Finally, by taking the fractal behavior of the pore space into consideration, the total pore volume of the rock would be

$$
V=V\left(<r_{\max }\right)=C \pi\left(r_{\max }^{3-D}-r_{\min }^{3-D}\right),
$$

where $r_{\text {min }}$ and $r_{\text {max }}$, respectively, are the smallest and biggest pore radiuses. Then, the cumulative volume fraction of pores with radiuses smaller than $r$ should be

$$
V_{c}=\frac{V(<r)}{V_{\text {total }}}=\frac{r^{3-D}-r_{\min }^{3-D}}{r_{\max }^{3-D}-r_{\min }^{3-D}} .
$$

And if $r_{\min } \ll r$, then we have

$$
V_{c}=\frac{V(<r)}{V_{\text {total }}}=\frac{r^{3-D}}{r_{\text {max }}^{3-D}} .
$$




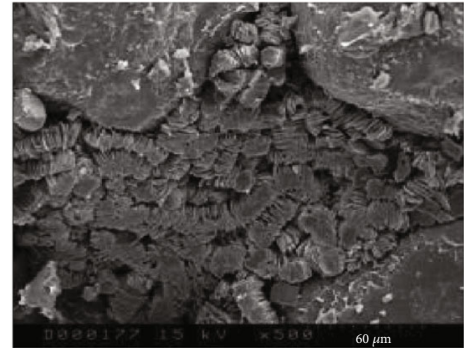

(a)

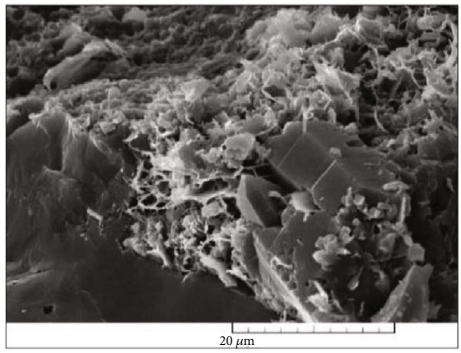

(c)

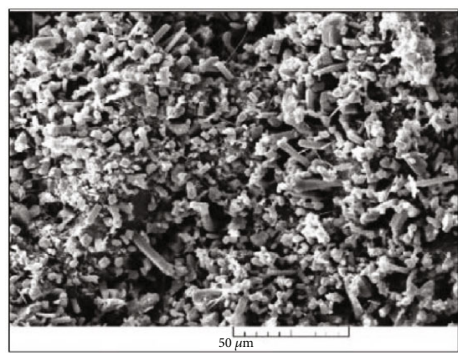

(e)

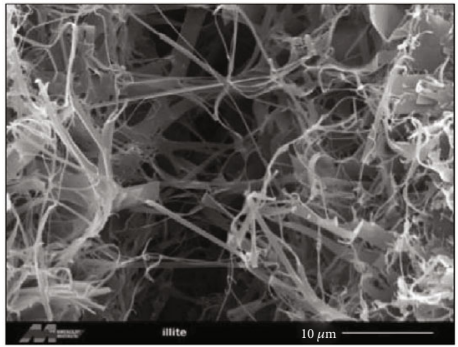

(b)

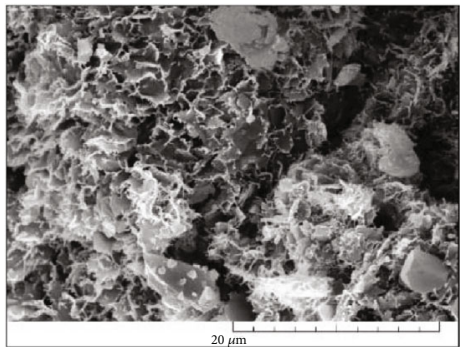

(d)

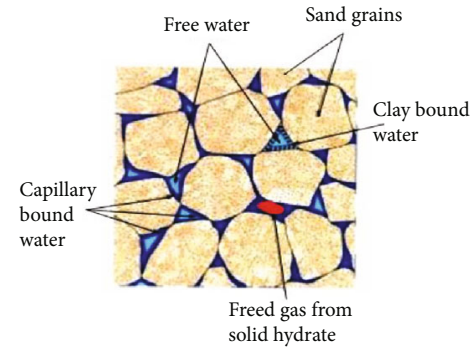

(f)

FIGURE 2: How clay minerals occupy pore body/throat which would damage the permeability of the formation. (a) Kaolinite filling pores inside the sandstone [2]. (b) Illite gathering at the pore body and pore throats (image reproduced from the "Images of Clay Archive" of the Mineralogical Society of Great Britain \& Ireland and the Clay Minerals Society (https://www.minersoc.org/images-of-clay.html)). (c) Mixed illite-smectite, (d) smectite, (e) chloride, and (f) schematic diagram of bound water caused by the presence of clays. (c-e) Images are from the core samples of the study area.

And eventually, we have

$$
V_{c}=\frac{V(<r)}{V_{\text {total }}}=\left(\frac{r}{r_{\max }}\right)^{3-D},
$$

where $D$ is the fractal dimension.

The detailed explanation about calculating lacunarity and succolarity is perfectly reviewed and provided in the work of Xia et al. [47]. However, in a simple sense, it would be stated that to measure lacunarity, a square box with a side of $r$ moves over the image and the number of pores enclosed inside the box $\left(n_{p(r)}\right)$ and the number of boxes $\left(n_{B(r)}\right)$ are recorded. A probability density function of pore distribution, $P\left(n_{p(r)}\right)$, is then calculated using the division of $n_{p(r)}$ over $n_{B(r)}$, i.e., $\left(n_{p(r)}\right) /\left(n_{B(r)}\right)$. Then, a statistical moment function is established as

$$
X_{P}^{q}(r)=\sum_{n_{p(r)}} n_{p(r)}{ }^{q} P\left(n_{p(r)}\right) .
$$

Therefore, the lacunarity $\Lambda(r)$ could be obtained as the statistical moment function when $q=2$ divided by squared value of $q=1$ for $X$ as $[47,64]$

$$
\Lambda(r)=\frac{X_{P}^{2}(r)}{\left(X_{P}^{1}(r)\right)^{2}} .
$$

This value is normalized then to prevent the effect of porosity on the measurement results as

$$
\lambda(r)=\frac{\Lambda(r)-\Lambda_{\min }}{\Lambda_{\max }-\Lambda_{\min }}=\varphi \frac{\Lambda(r)-1}{1-\varphi}
$$

where $\lambda(r)$ is the normalized lacunarity.

Based on this principle idea and calculations, we needed to investigate the fractal properties of the pore space inside the clay minerals observed on 2D SEM images. In the present study, the fractal analyses were conducted using the box counting technique, where the fractal dimension and lacunarity were identified. We determined the lacunarity from 

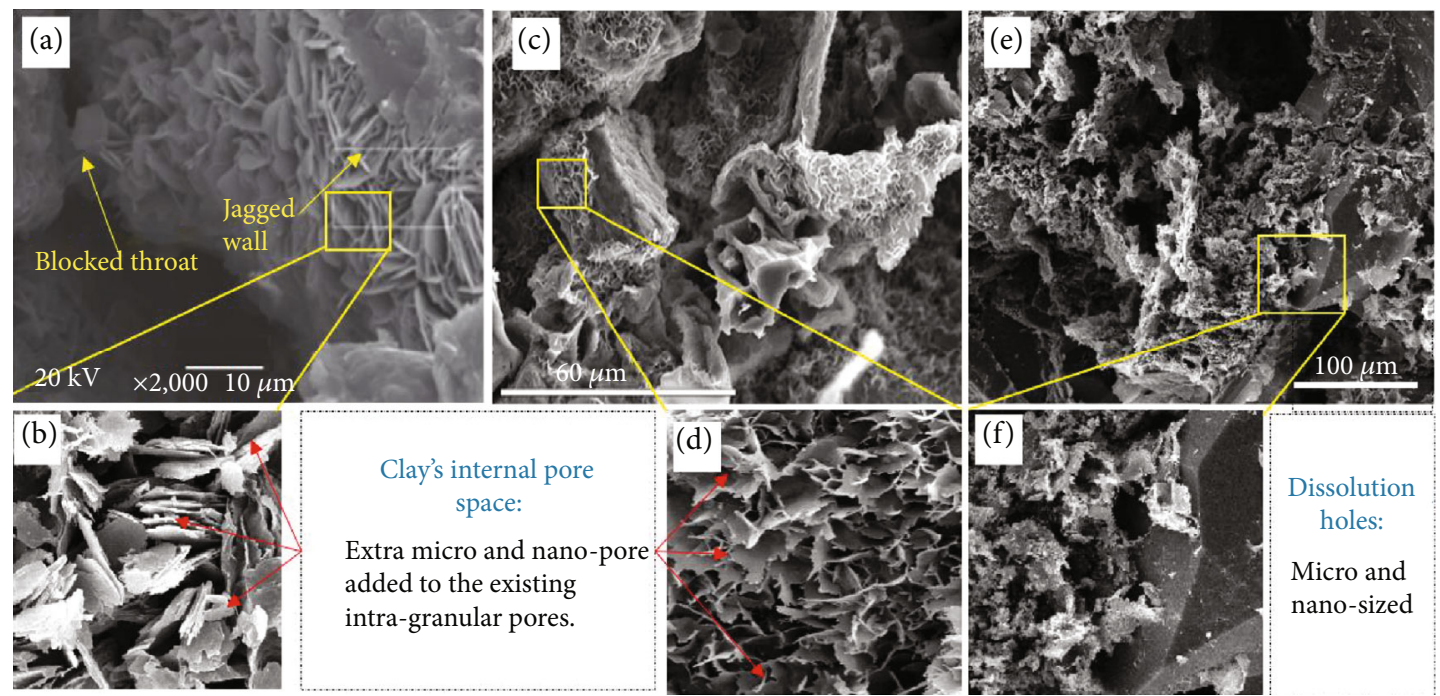

Clay's internal pore space:

Extra micro and nano-pore added to the existing intra-granular pores.
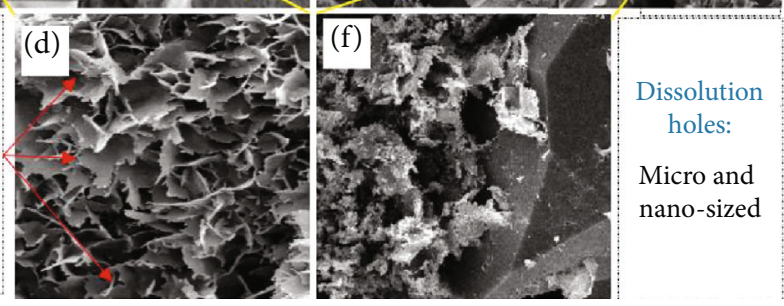

FIgURE 3: Conceptual representation of the adhering of clays to the pore wall surfaces and complicating the intragranular pore space: (a) chlorite (after [65]), (b) chlorite (study area), (c) smectites (image reproduced from the "Images of Clay Archive" of the Mineralogical Society of Great Britain \& Ireland and the Clay Minerals Society (https://www.minersoc.org/images-of-clay.html)), and (d) smectites (study area). (e, f) How dissolution holes add extra pores to the reservoir's pore space (study area). It is worth noting that (b) and (d) are conceptual, not the real magnification of (a) and (c), respectively; however, (f) is the real magnification of (e). On these images, the big pores show the intragranular pore space.

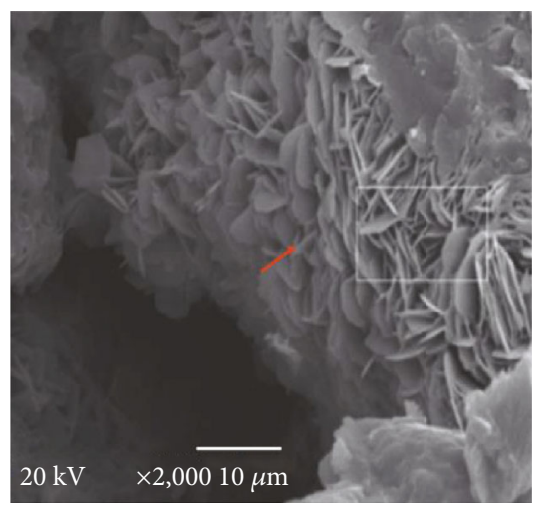

(a)

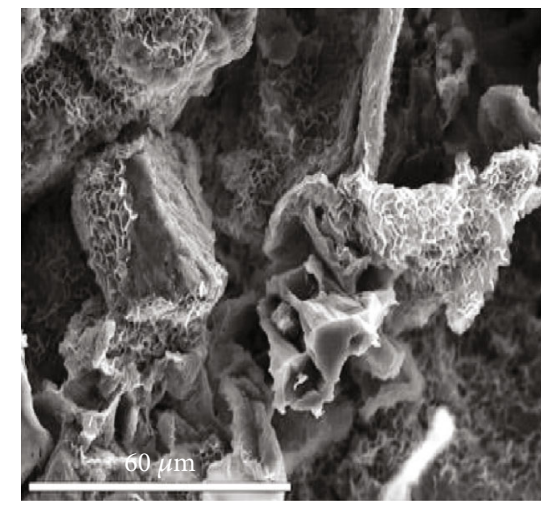

(b)

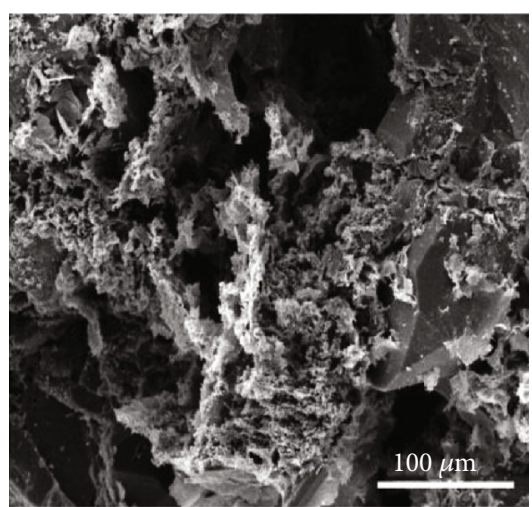

(c)

FIGURE 4: The original SEM images used in the present paper (Figure 3) provided in higher resolution for the reader's reference: (a) chlorite (after [65]); (b) smectites (image reproduced from the "Images of Clay Archive" of the Mineralogical Society of Great Britain \& Ireland and the Clay Minerals Society (https://www.minersoc.org/images-of-clay.html)); (c) dissolution holes (study area). 


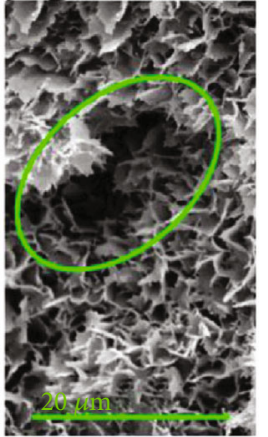

(a)

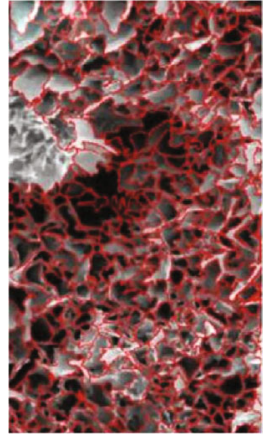

(b)

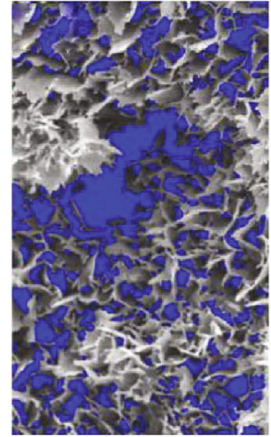

(c)

FIGURE 5: Comparing the results of segmenting the problematic sections of the SEM image (a) by two methods of manual segmentation (b) and grayscale-based thresholding (c), where the latter approach did not perform as precisely as the former one.

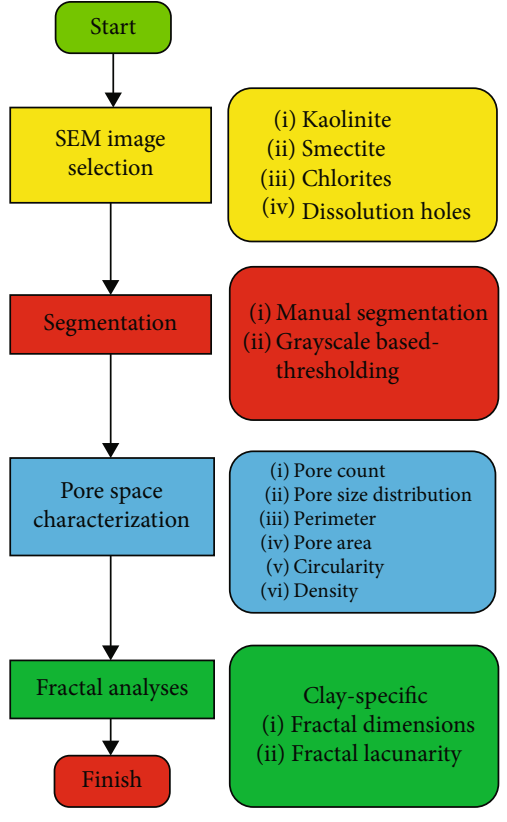

FIGURE 6: Workflow of the present study.

the pixel distribution in the images based on the variations of pixel density for different grid sizes in the box counting task. In this method, the pixel distribution for one grid size, $r$, was calculated by counting the number of pixels in each $r$-sized box in a grid placed on the image. The variation is obtained from some basic statistical parameters that were calculated for each $r$, such as mean of the number of pixels per box $(\delta$ ) , the standard deviation of pixels per box $(\zeta)$, and coefficient of variation for pixels per box $=(\zeta / \delta) 2=\lambda$. This way, there was a $\lambda$ value for each $r$ in a particular grid orientation $(g)$, meaning that we had a set of $r$ 's and a set of $g$ 's. Under such a condition, there was never a single $\lambda$, but we had a series of $\lambda(r, g)$. Therefore, the fundamental value of lacunarity could be calculated as

$$
\lambda(r, g)=\left(\frac{\zeta}{\delta}\right)_{r, g}^{2}
$$

where $\lambda(r, g)$ is the lacunarity defined for a specific grid size in a specific grid orientation, meaning that $\lambda(r, g)$ is recorded per $r$ per $g$. Since there were many $\lambda$ 's, the method of obtaining image lacunarity was to first calculate lacunarity over all grid sizes at one grid orientation (by averaging) and then average these mean values again to obtain the image lacunarity in all orientations. In other words, $L$ is the mean of the means. If we consider the following:

(i) $\Lambda(g)$ as lacunarity over all sizes at one grid orientation

(ii) $L$ as lacunarity over all grid orientations as the mean of $\Lambda(g)$ 's

then, $\Lambda(g)$ and $L$ could be statistically calculated as

$$
\begin{gathered}
\Lambda(g)=\lambda(r, g)_{\mathrm{avg}}=\frac{\sum_{1}^{N(r)} \lambda(r, g)}{N(r)}, \\
L=\frac{\sum_{1}^{N(g)} \Lambda(g)}{N(g)}
\end{gathered}
$$

where $N(r)$ is the number of grid sizes and $N(g)$ is the number of grid origins. The reader is referred to [47-49] for the relevant calculation methods of succolarity.

\section{Materials and Methods}

Core samples were obtained from the study area and were prepared for recording SEM images. Then, a limited group of obtained images, i.e., subject images, that fulfilled the basic requirements for this research was chosen to be studied. The requirements were as follows: (a) the imaged area covered at least one type of the desired clay groups or dissolution holes, (b) had enough resolution to show the pore space precisely, and (c) has the least possible amount of "depth of field" problem and (d) the imaging lens looked at the desired structure right from the front view, not from an inclined angle. Depth of field indicates the situation where several small pores that exist inside a bigger pore are all segmented as a single big pore which is not fundamentally correct. Therefore, while recording the images, we specifically focused on clay minerals. It is worth mentioning that the samples were regular 


\section{Kaolinite A}

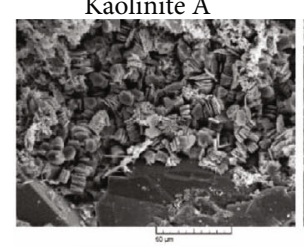

Smectite A

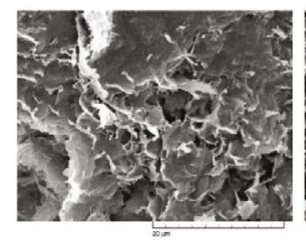

Kaolinite A

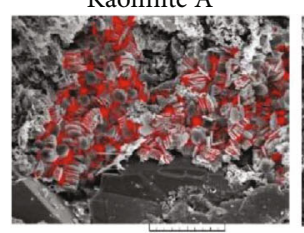

Smectite A

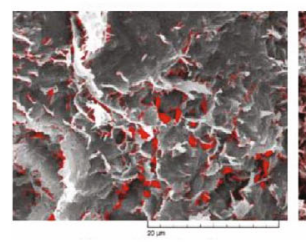

Kaolinite A

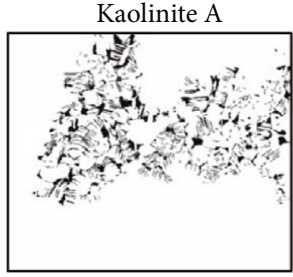

Smectite A

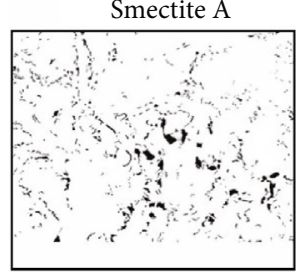

Kaolinite B

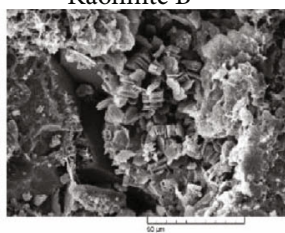

Smectite B

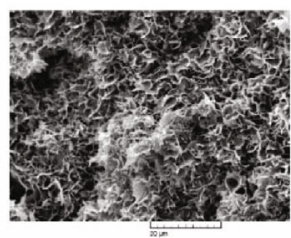

Chlorite A

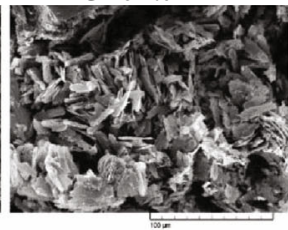

Dissolution holes A

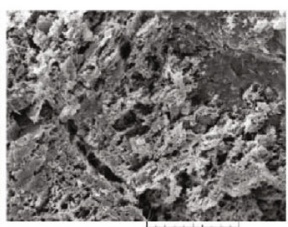

(a)

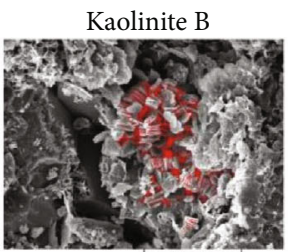

Smectite B

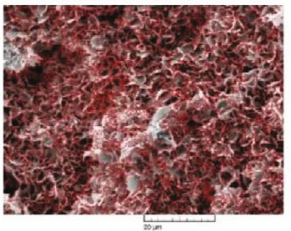

Chlorite A

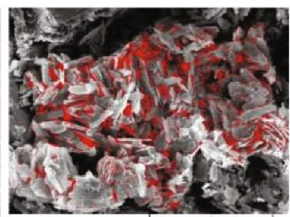

Dissolution holes A

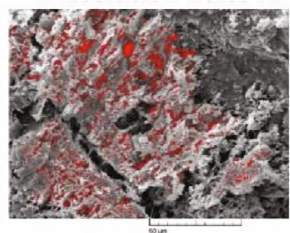

(b)
Kaolinite B

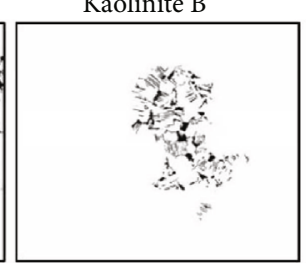

Smectite B

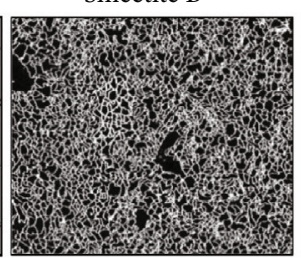

Chlorite A

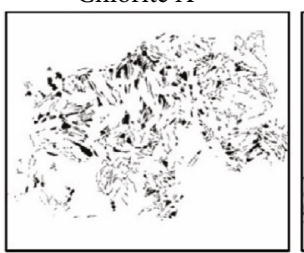

Dissolution holes A

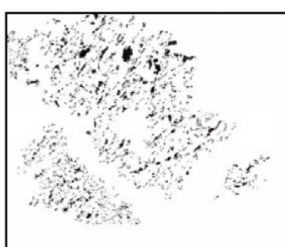

Chlorite B

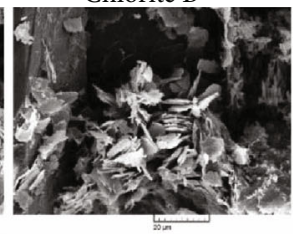

Dissolution holes B

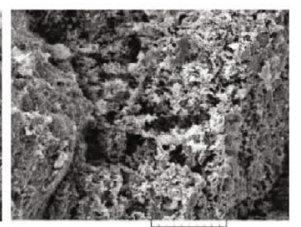

Chlorite B

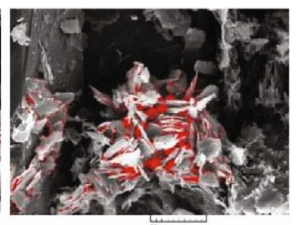

Dissolution holes B

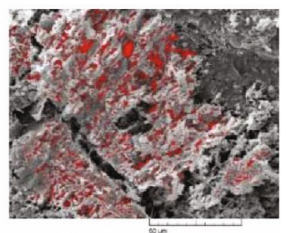

(c)

FIGURE 7: Original SEM images for segmentation (a), manually segmented images (b), and binarized pore space with CIPS in black color (c).

core samples and the obtained images were for the clays inside the core, not for any pure clay minerals. Various clays possess different pore structural properties. While kaolinites and illites gather in stacks and block the pore throats, smectites and chlorites grow on the surface of the large minerals and appear as a jagged layer with an extremely irregular surface. This way, intragranular pores are either closed or are surrounded by rough and jagged walls. Figure 2 illustrates the most important challenges that are created by clay minerals in the hydrocarbon reservoirs. The adhering phenomenon of smectites and chlorites to the pore wall surfaces is stunningly observed in Figure 3 (see Figure 4 for highresolution images). As shown, the intragranular pores appear as big empty rooms blocked at some ends and surrounded by clay-covered walls. The presence of such minerals with a pore size distribution sometimes much smaller than the pore space totally alters the PSD of the porous media as discussed earlier.

With this in mind, in the present study, we recorded images of smectites, chlorites, kaolinites, and dissolution holes with the least possible amount of the "depth of field" problem. In the next step, the clay's internal pore space 
Kaolinite A
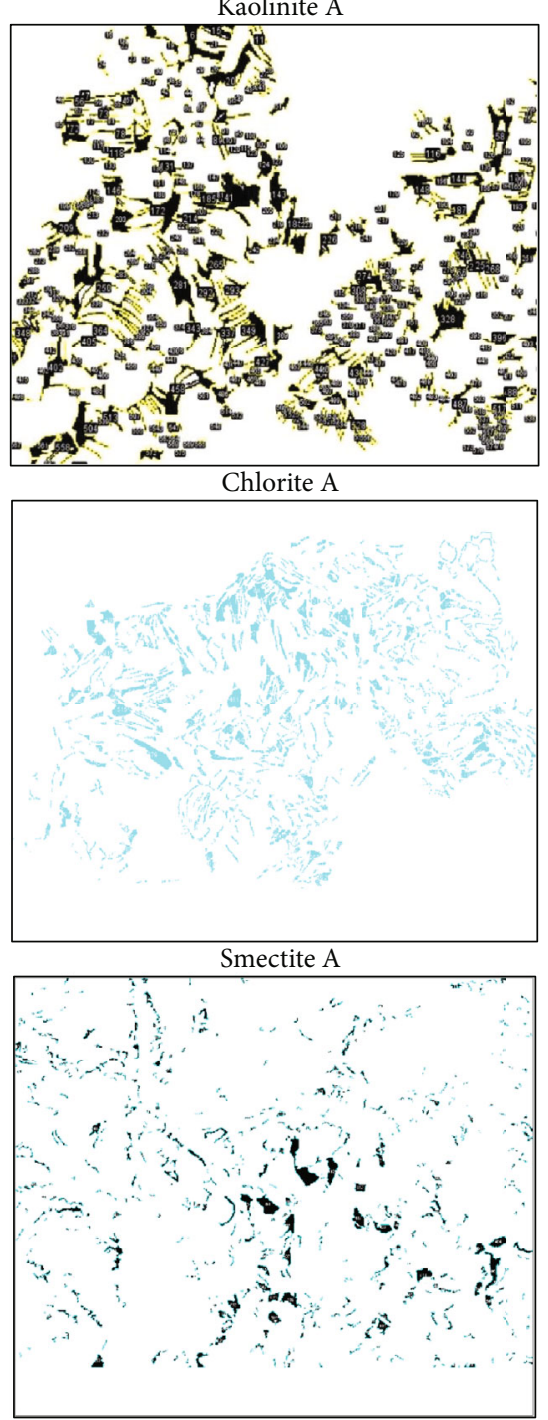

Dissolution holes A

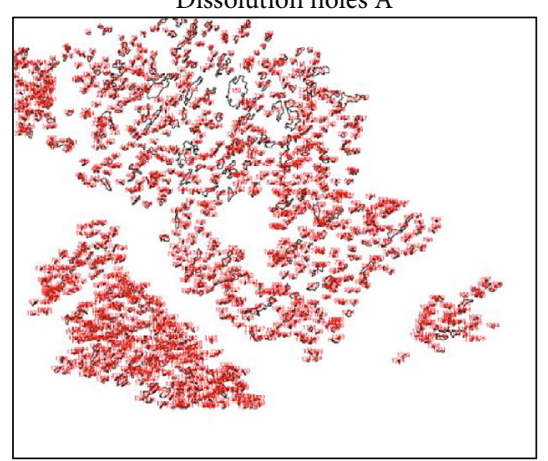

Kaolinite B
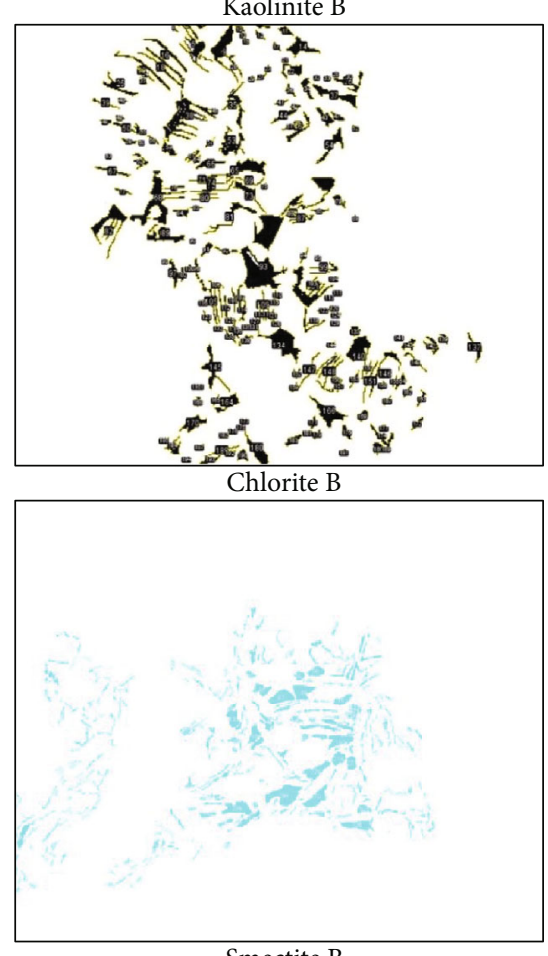

Smectite B

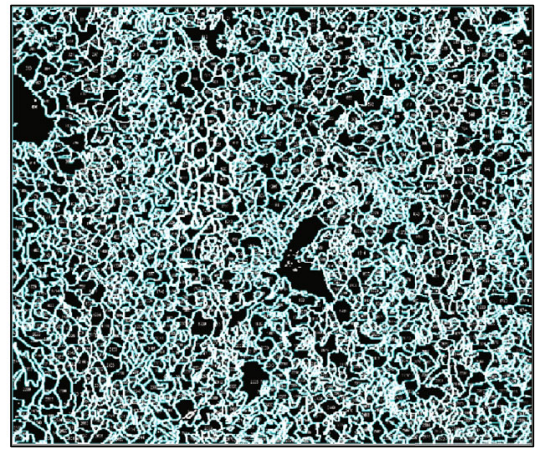

Dissolution holes B

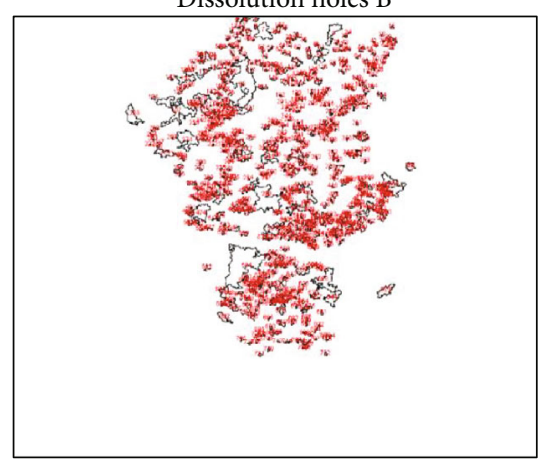

Figure 8: Counted number of pixels in each pore.

(CIPS) was segmented manually. Manual segmentation is the process of coloring a particular group of pixels which could be done using any image processing program. Manual segmentation was the only reliable approach for this purpose. This is because the existing thresholding or segmentation methods rely on the grayscale value and could not clearly distinguish the CIPS. In other words, these methods consider CIPS a part of a bigger hole and could not be efficient enough for precisely determining several pores included in a bigger hole scattered on the surface of mineral grains. This phenomenon is depicted in Figure 5. After segmentation, the image analyses were used for extracting the detailed pore structural information using the open-source image processing program ImageJ. It is worth noting that while we focused on kaolinite, smectite, chlorite, and dissolution holes, we could not characterize the illites. This is because illite appears as needles 

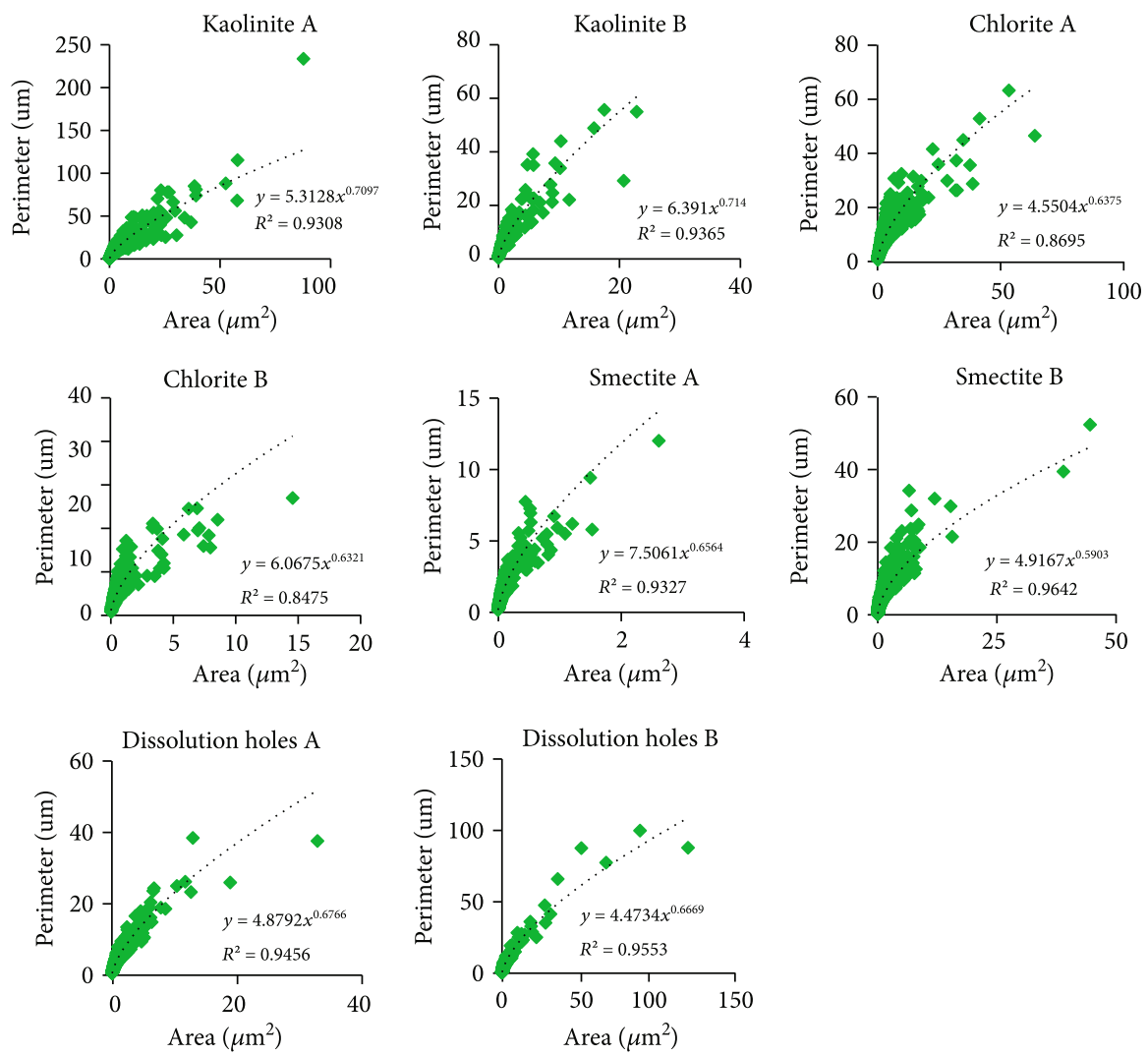

(a)
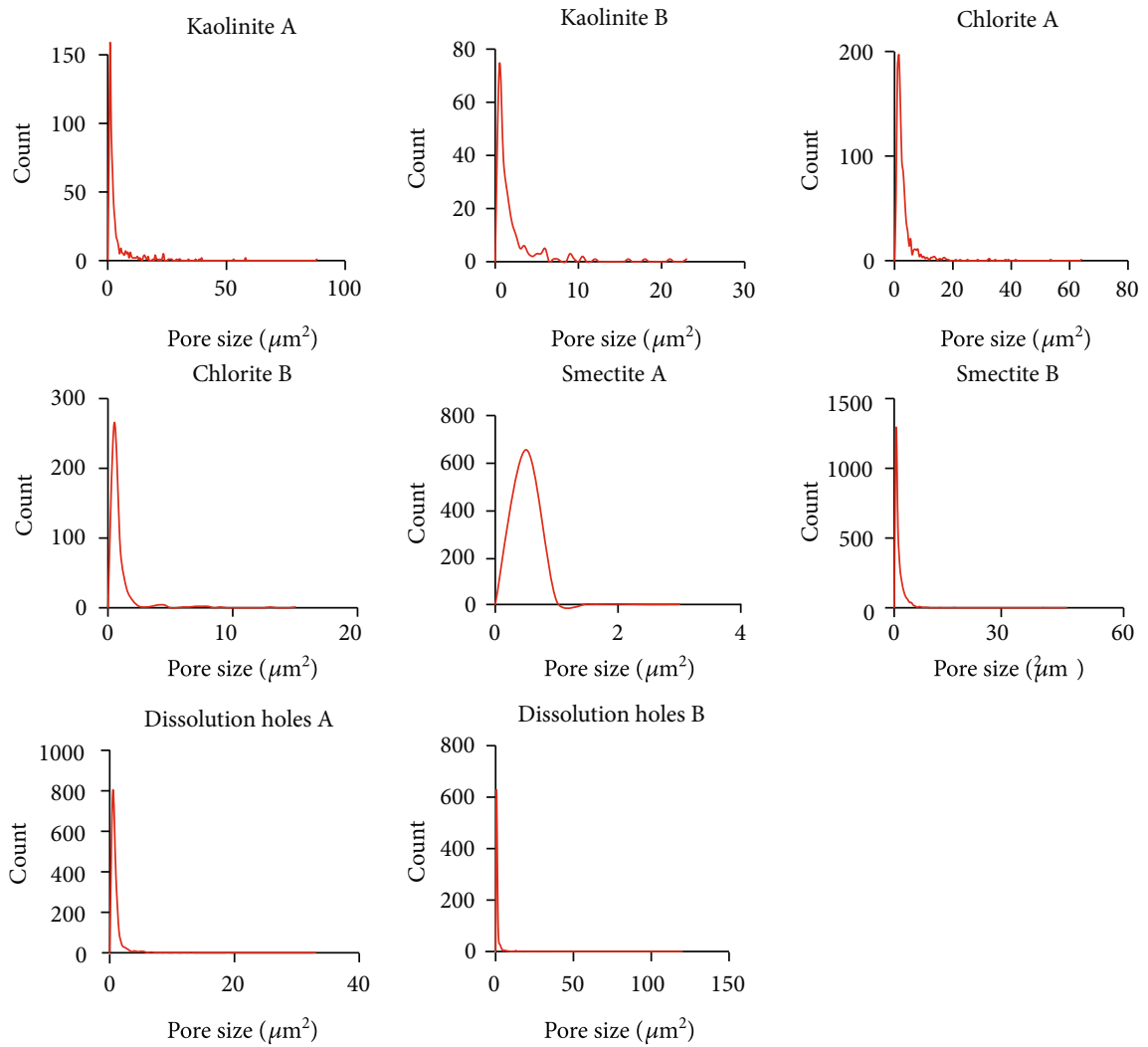

(b)

Figure 9: The results of analyzing the internal structure of different clay minerals including perimeter-area crossplot (a) and pore size distribution (b). 
TABLE 1: Interpretation of PSD, lacunarity, and fractal dimension analyses for the internal pore space of different clay groups and dissolution holes obtained from the box counting method.

\begin{tabular}{|c|c|c|c|c|c|c|c|c|}
\hline & Kaolinite A & $\begin{array}{c}\text { Kaolinite } \\
\text { B }\end{array}$ & Chlorite A & Chlorite B & Smectite A & Smectite B & $\begin{array}{c}\text { Dissolution } \\
\text { holes A }\end{array}$ & $\begin{array}{l}\text { Dissolution } \\
\text { holes B }\end{array}$ \\
\hline $\begin{array}{l}\text { SEM image resolution } \\
(\mu \mathrm{m})\end{array}$ & 0.250 & 0.187 & 0.294 & 0.130 & 0.055 & 0.100 & 0.197 & 0.250 \\
\hline Fractal dimension $(D)$ & 1.63 & 1.56 & 1.66 & 1.51 & 1.53 & 1.85 & 1.63 & 1.65 \\
\hline Correlation coefficient & 0.9981 & 0.9974 & 0.9978 & 0.9985 & 0.9857 & 0.9970 & 0.9979 & 0.9980 \\
\hline Lacunarity $(L)$ & 0.55 & 0.63 & 0.55 & 0.99 & 0.82 & 0.18 & 0.56 & 0.62 \\
\hline $\begin{array}{l}\text { Circularity (average of all } \\
\text { pores) }\end{array}$ & 0.44 & 0.41 & 0.56 & 0.48 & 0.59 & 0.63 & 0.71 & 0.76 \\
\hline $\begin{array}{l}\text { Box size range }(r) \text {, step } \\
\text { size }=1\end{array}$ & [5-211] & {$[5-144]$} & {$[5-233]$} & [5-185] & [5-259] & {$[5-260]$} & [5-259] & [5-239] \\
\hline $\begin{array}{l}\text { Perimeter-area } \\
\text { correlation }\end{array}$ & 0.9308 & 0.9365 & 0.8695 & 0.8475 & 0.9327 & 0.9642 & 0.9456 & 0.9553 \\
\hline $\begin{array}{l}\text { Processed image size } \\
\text { (pixels) }\end{array}$ & $768 \times 575$ & $768 \times 575$ & $768 \times 575$ & $768 \times 575$ & $768 \times 575$ & $768 \times 575$ & $768 \times 575$ & $768 \times 575$ \\
\hline $\begin{array}{l}\text { Processed image size } \\
\left(\mu \mathrm{m}^{2}\right)\end{array}$ & 27600 & 15422 & 38170 & 7463 & 1336 & 4416 & 17138 & 27600 \\
\hline $\begin{array}{l}\text { Pore count density (per } \\
100 \mu \mathrm{m}^{2} \text { ) }\end{array}$ & 2.25 & 1.31 & 2.72 & 5.44 & 50.46 & 61.30 & 8.17 & 4.88 \\
\hline $\begin{array}{l}\text { Average pore size density } \\
\left(\mu \mathrm{m}^{2}\right)\end{array}$ & 3.92 & 1.96 & 3.03 & 0.75 & 0.01 & 1.02 & 0.75 & 1.27 \\
\hline Average perimeter $(\mu \mathrm{m})$ & 11.86 & 8.89 & 8.23 & 4.36 & 1.42 & 4.26 & 3.56 & 4.16 \\
\hline Pore count & 620 & 202 & 1040 & 406 & 674 & 2707 & 1400 & 1346 \\
\hline $\begin{array}{l}\text { Pore size distribution } \\
\text { range }\left(\mu \mathrm{m}^{2}\right)\end{array}$ & [0.06-87.69] & {$[0.03-23.0]$} & {$[0.08-64.0]$} & {$[0.05-14.57]$} & {$[0.003-2.62]$} & {$[0.01-44.54]$} & [0.04-32.83] & [0.06-119.75] \\
\hline Perimeter range $(\mu \mathrm{m})$ & {$[0.7-233.4]$} & {$[0.5-55.75]$} & {$[0.8-63.2]$} & {$[0.7-21.6]$} & {$[0.015-12.02]$} & {$[0.28-52.43]$} & {$[0.55-38.45]$} & {$[0.7-99.97]$} \\
\hline
\end{tabular}

and segmenting its internal pore space on 2D SEM images is indeed not feasible. This could be done through 3D FIB-SEM imaging. Figure 6 illustrates the workflow of the present study.

\section{Results: Fractal Characteristics of Clay Minerals and How They Alter the Pore Size Distribution}

The original and segmented images are represented in Figures 7(a) and 7(b). While segmenting the SEM images, our target was the clay minerals so we merely segmented the pore space generated by these clays. That is why some images might seem partly segmented in the middle part of Figure 7, e.g., kaolinite B and chlorite B. Once done with segmentation, we binarized the resultant images. The results of binarization are presented in Figure $7(\mathrm{c})$. The binarization results clearly illustrate the difference among the pore types of different clay groups and also the morphological differences of clays and dissolution holes. While narrow long pores widely exist within kaolinite and chlorite, the pores in smectites and dissolution holes are more circular. Then, the number of pores was counted. Subsequently, the perimeter and the area of every pore were calculated by counting the number of pixels encompassed inside it as represented in Figure 8.
In this figure, four different kinds of image masks are illustrated. The mask used for kaolinite images indicated the number of pores, and the mask adopted for chlorite pores indicated the number of pixels in each pore. The mask on smectite images is another representation of the number of pixels, and finally, the mask applied to the dissolution hole image shows the outline of the pores and the encompassed pixel counts. It should be noted that all these four different masks could be obtained for all images.

For all eight images, when the perimeters of the segmented pores were plotted against their areas, it was found that the CIPS showed strong fractal properties (Figure 9(a)). Hence, in the next step, the fractal geometry theory was implemented to study the CIPS. Herein, we calculated the fractal dimension and fractal lacunarity of the segmented pore spaces. The results of these calculations are represented and interpreted in Table 1. After all, it was time to extract clay's pore size distribution and determine how these minerals add to the complexity of the porous media and alter the pore size distribution. The PSD of kaolinite, smectite, chlorite, and dissolution holes are illustrated in Figure 9(b). As can be seen, the number of small pores with sizes of $<10 \mu \mathrm{m}$ was significantly high in all the studied cases. This is also deducible from the frequency plots of the pore area and perimeter values depicted in Figures 10 and 11, respectively. After all, the fractal dimension and lacunarity 
Kaolinite A

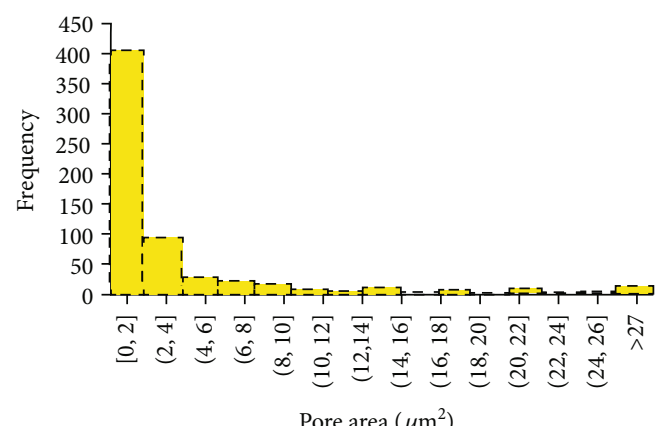

Chlorite A

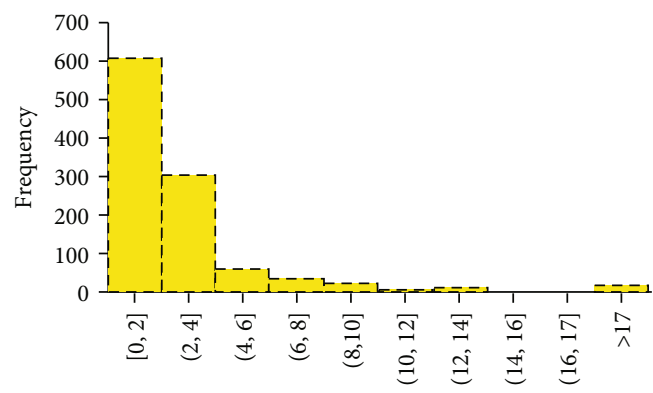

Pore area $\left(\mu \mathrm{m}^{2}\right)$
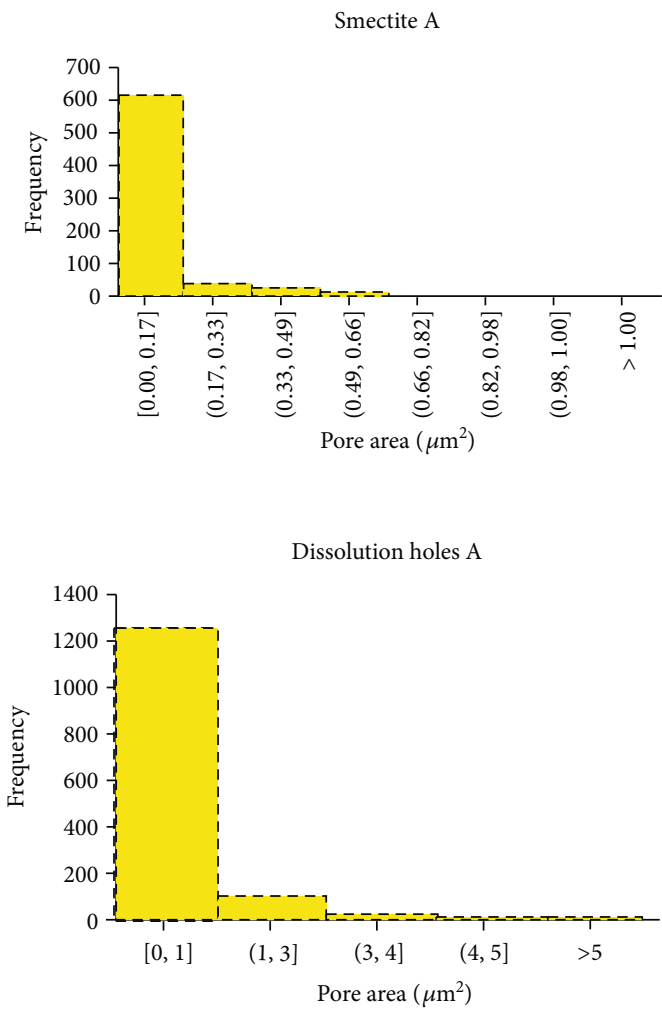

Kaolinite B

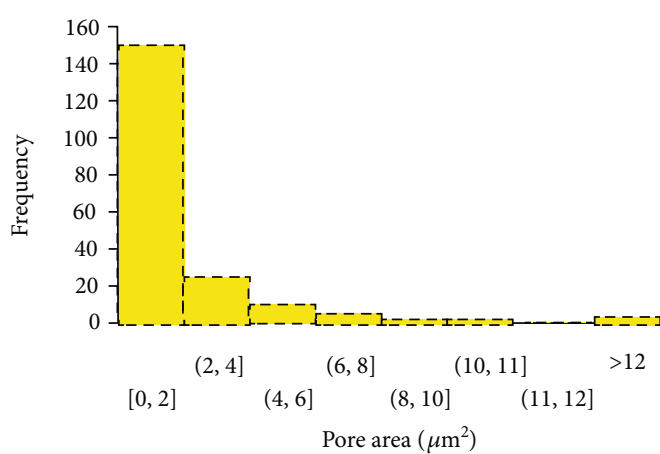

Chlorite B

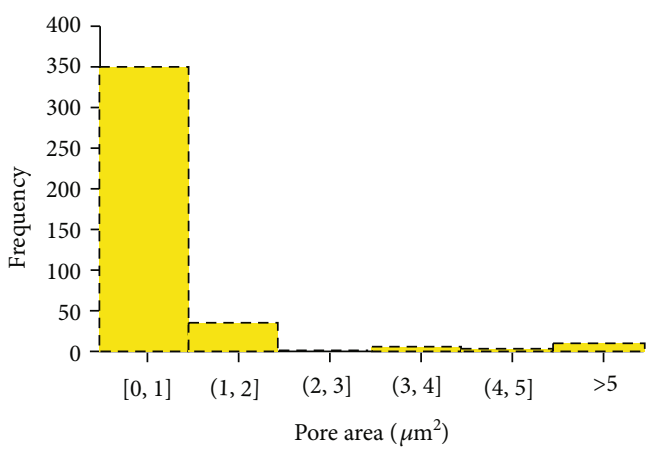

Smectite B

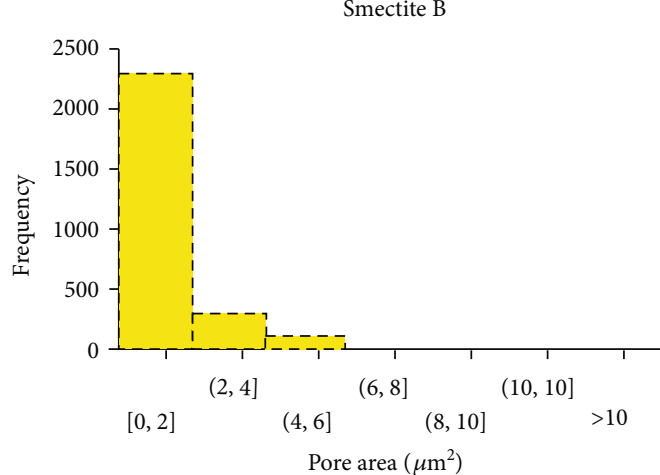

Dissolution holes B

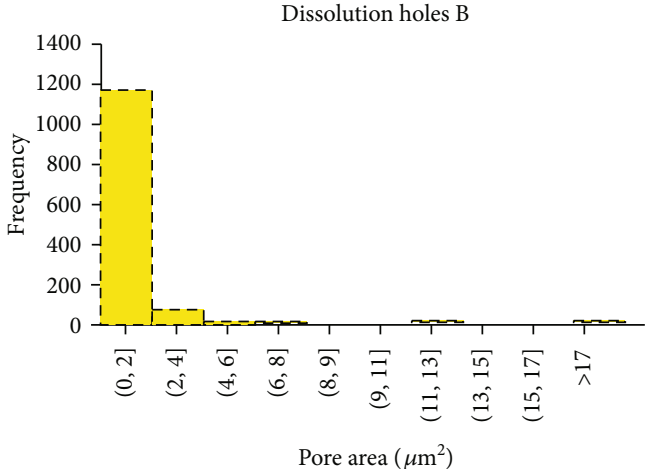

FIGURE 10: The results of analyzing the internal structure of different clay minerals (area frequency).

analyses were conducted for the internal pore space of different clays and dissolution holes using the box counting method as represented. The results of these analyses are provided in Figure 12. The graphs in this figure indicate that there existed similar patterns in pore structural properties of the studied cases. Nevertheless, the detailed interpretation and comparison of these results are provided in the next section. 
Kaolinite A

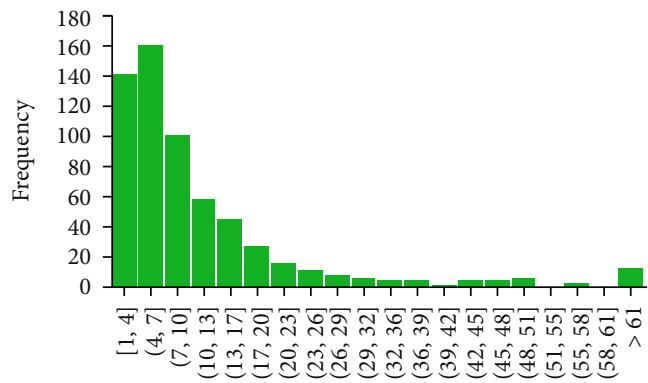

Pore perimeter $(\mu \mathrm{m})$

Chlorite A

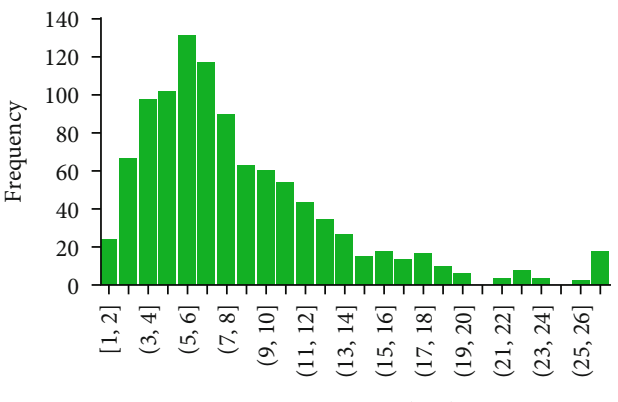

Pore perimeter $(\mu \mathrm{m})$

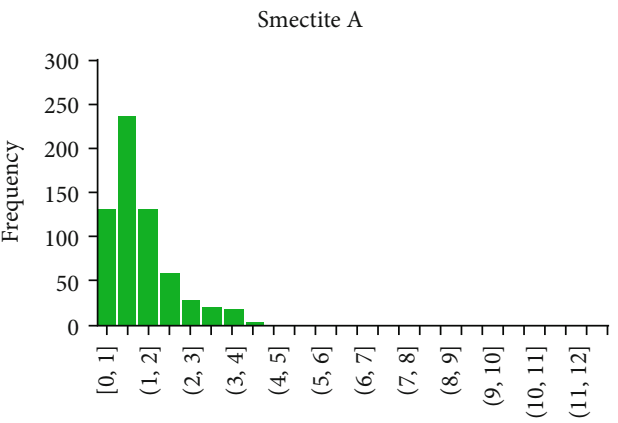

Pore perimeter $(\mu \mathrm{m})$

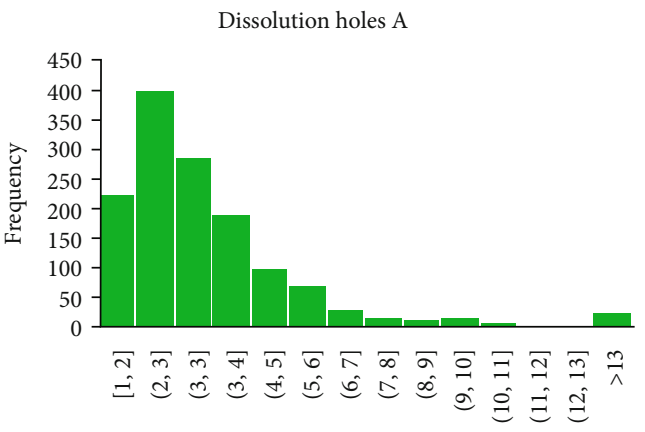

Pore perimeter $(\mu \mathrm{m})$
Kaolinite B

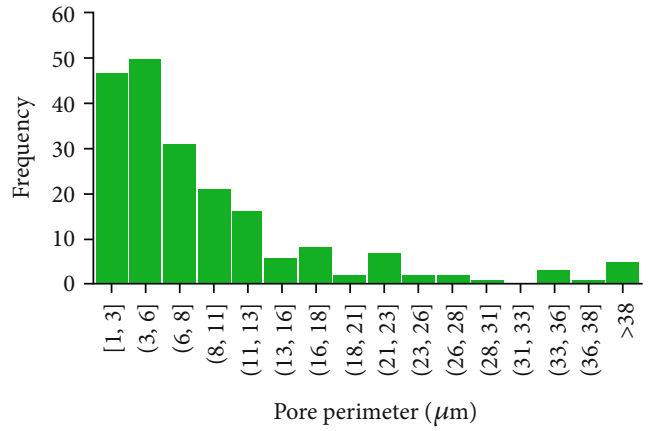

Chlorite B

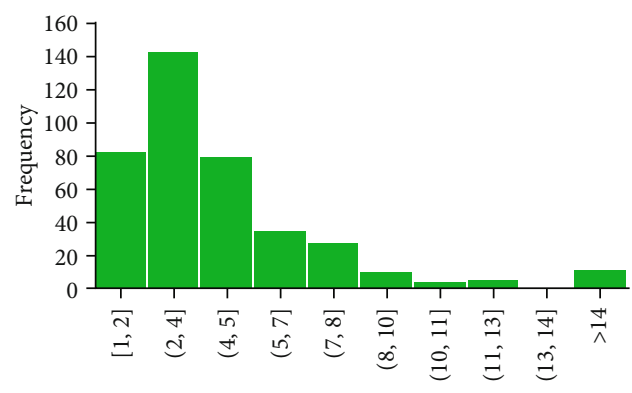

Pore perimeter $(\mu \mathrm{m})$

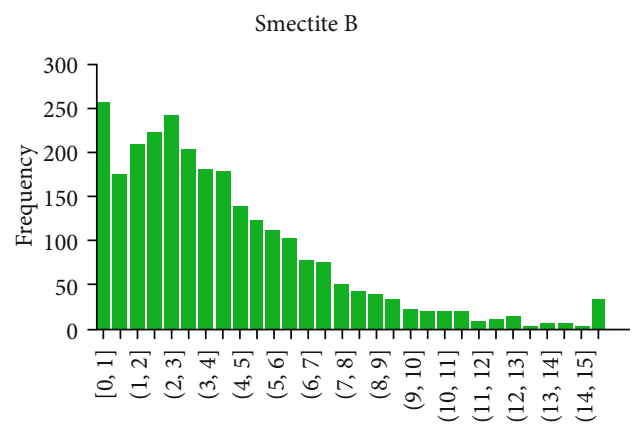

Pore perimeter $(\mu \mathrm{m})$

Dissolution holes B

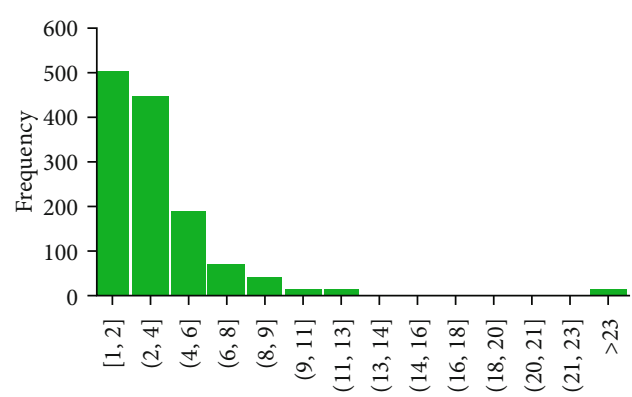

Pore perimeter $(\mu \mathrm{m})$

FIGURE 11: The results of analyzing the internal structure of different clay minerals (perimeter frequency).

\section{Discussion}

The analysis of the data revealed that the studied clay minerals, i.e., smectite, chlorite, and kaolinite as well as the disso- lution holes, significantly alter the internal pore space of the gas hydrate-bearing sediments and sandstone. This phenomenon is graphically depicted in Figure 9 and was analyzed quantitatively as represented in Figures $9-11$, as well as 

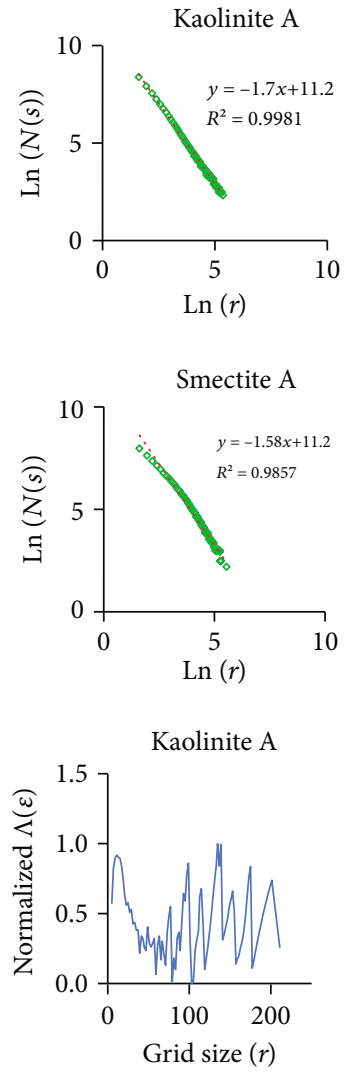

Smectite A

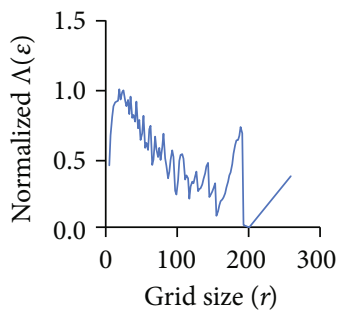

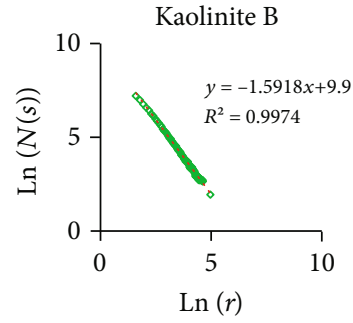
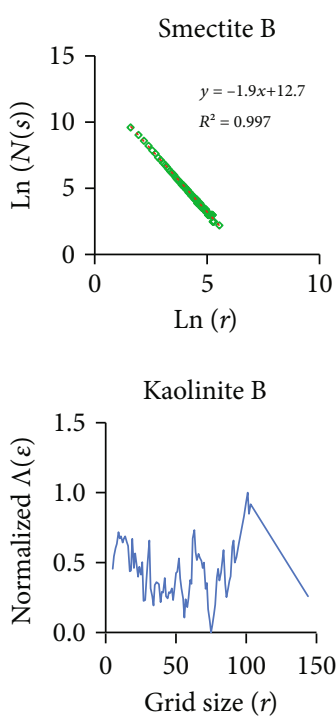

Smectite B

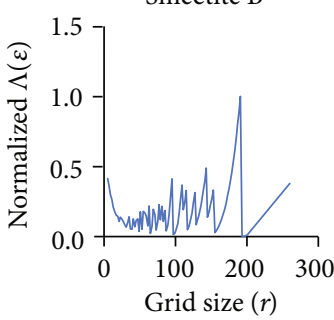

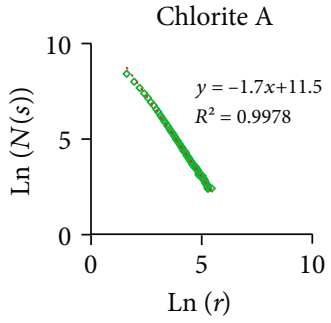
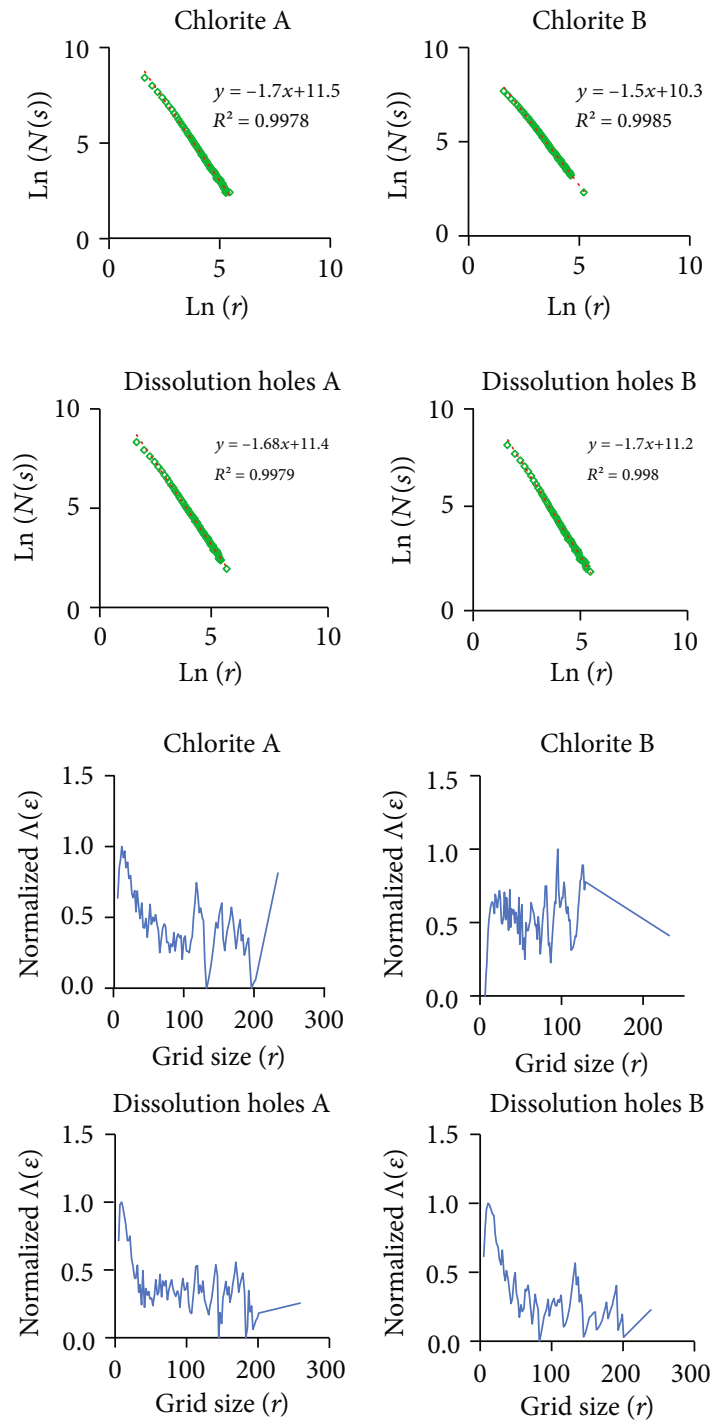

Figure 12: The results of fractal analyses of the internal structure of different clay minerals including fractal dimension (top green scatterplots) and lacunarity (down blue curves).

Table 1. As can be seen from Table 1, dissolution holes had the widest pore size distribution and kaolinite had a wider PSD than smectite and chlorite being almost twice. Meanwhile, for all analyzed clays, a significant amount of variations was observed in the number of pores with different sizes, which could be understood from the fluctuations of the distribution and frequency curves in Figures 9-11. Such fluctuations were the most for, respectively, kaolinite, smectite, and chlorite, while dissolution holes did not represent significant fluctuations. When we consider this phenomenon with the frequency curves together, it can be found that while dissolution holes and smectite represented a large number of small-sized pores, kaolinite and chlorite contained a larger number of bigger pores. It is worth noting that the concepts of "small" and "large" used here are relative and both indicate the microscopic pores. What is more, the pores in the dissolution holes, smectite, chlorite, and kaolinite had, respectively, the smallest to the largest range of perimeters.
However, the average circularity was the largest for dissolution holes (0.74) and then smectite pores (0.61) compared to the narrow elongated pores in chlorite (0.52) and kaolinite $(0.42)$. Circularity falls in the range of $0-1$ where 1 indicates a perfect circle.

Figure 12 indicates that the grid size had a significant effect on the lacunarity and this effect did not follow any regular trend as expected. However, for the three kinds of clay minerals, the fractal dimension and lacunarity had distinct differences with $D$ and $L$, respectively, falling in the ranges of 1.51-1.85 and 0.18-0.99. In detail, the average $D$ for kaolinite, chlorite, smectite, and dissolution holes was, respectively, $1.60,1.59,1.69$, and 1.64. However, the average $L$ was, respectively, $0.59,0.77,0.50$, and 0.59 . Interestingly, the total number of observed pores was the most for smectite and for, respectively, dissolution holes, chlorite, and kaolinite. Accordingly, the average pore count density in $100 \mu \mathrm{m}^{2}$ of the studied images of dissolution holes (55.88) was much 
TABLE 2: Fractal and pore size distribution characteristics of various clays and dissolution holes.

\begin{tabular}{lcccc}
\hline & Kaolinite & Chlorite & Smectite & Dissolution holes \\
\hline Fractal dimension $(D)$ & 1.60 & 1.59 & 1.69 & 1.64 \\
Lacunarity $(L)$ & 0.59 & 0.77 & 0.50 & 0.59 \\
Circularity (average of all pores) & 0.42 & 0.52 & 0.61 & 0.74 \\
Average pore count density $\left(\right.$ per $\left.100 \mu \mathrm{m}^{2}\right)$ & 1.78 & 4.08 & 55.88 & 6.52 \\
Average pore size density $\left(\mu \mathrm{m}^{2}\right)$ & 2.94 & 1.89 & 0.56 & 1.01 \\
Average perimeter $(\mu \mathrm{m})$ & 10.38 & 6.30 & 2.84 & 3.86 \\
\hline
\end{tabular}

greater than that of smectite (6.52), chlorite (4.08), and kaolinite (1.78). This phenomenon is obviously the result of the morphological structures. While in dissolution holes, there are many dissolved portions of the mineral surface, in smectite, there are thin walls among adjacent pores, and in chlorite and kaolinite, there exist thick clay boundaries forming a disseminated pore space. All in all, clays could alter the pore size distribution by adding about $1.31-61.30$ pores $/ 100 \mu \mathrm{m}^{2}$ for which the size distribution falls in the range of 0.003-87.69 $\mu \mathrm{m}^{2}$. Likewise, dissolution pores added complicate the pore structure by adding about $4.88-8.17$ pores $/ 100 \mu \mathrm{m}^{2}$ for which the size distribution falls in the range of $0.04-119.75 \mu \mathrm{m}^{2}$. All these observations prove the aforementioned hypothesis that clay minerals and dissolution holes alter the intragranular pore space significantly and make the pore space characteristics more complicated. Finally, the present study would put forth the data in Table 2 as the fractal and pore size distribution characteristics of various clays and dissolution holes.

\section{Conclusion}

In the present study, we investigated the internal pore size distribution and pore density of various clays including kaolinite, smectite, chlorite, and dissolution holes. We then analyzed the resultant changes to the pore space of the reservoir rock media. Herein, we introduced the specific fractal properties of these clay groups which included their fractal dimension and lacunarity. The following conclusions could be drawn from the conducted study:

(i) All types of clays alter the pore space condition of the reservoir rock by adding a significant number of macro- and nanopores which are an additional component to the existing intragranular pore space

(ii) Pore structural properties of various clays showed notable differences from each other which implies that they would have dissimilar impacts on the reservoir

(iii) Pore structural properties of dissolution holes fell in the ranges almost close to those of the clays

(iv) The reservoir quality, fluid mobility and saturations, hydrocarbon production, water flooding and EOR, electrical properties, etc., of the reservoir, would certainly be modified under the impact of clay minerals (v) Some existing modeling and simulation techniques have not taken clay minerals into consideration. The observations in the present study infer that such techniques might need to be readjusted

After all, the authors would suggest the following subjects as the extension to the present study:

(i) Investigating the application of deep learning as the cutting-edge machine learning technique to study the pore structural properties of various clay minerals

(ii) Developing fractal-based models of the reservoir by considering how the presence of the clays could alter the size distribution of pore space and pore throats. These models need to go beyond merely considering the fractal dimension value $(D)$ and need to incorporate other properties such as lacunarity, succolarity, and circularity

\section{Data Availability}

The data is already included within the manuscript.

\section{Conflicts of Interest}

The authors declare that they have no conflicts of interest.

\section{Acknowledgments}

This research was funded by the "Taishan Scholar Talent Team Support Plan for Advantaged and Unique Discipline Areas" of China.

\section{References}

[1] X. L. Sun, C. Y. Lin, X. G. Zhang et al., "Characteristics and distribution of clay minerals and their effects on reservoir quality: Huagang Formation in the Xihu Sag, East China Sea Basin," Australian Journal of Earth Sciences, vol. 66, no. 8, pp. 11631174, 2019.

[2] M. J. Wilson, L. Wilson, and I. Patey, "The influence of individual clay minerals on formation damage of reservoir sandstones: a critical review with some new insights," Clay Minerals, vol. 49, no. 2, pp. 147-164, 2014.

[3] B. Karpiński and M. Szkodo, "Clay minerals-mineralogy and phenomenon of clay swelling in oil \& gas industry," Advances in Materials Science, vol. 15, no. 1, pp. 37-55, 2015. 
[4] G. E. Christidis, "Industrial clays," in Advances in the Characterization of Industrial Minerals, European Mineralogical Union Notes in Mineralogy, pp. 341-414, Mineralogical Society of Great Britain and Ireland, 2010.

[5] S. Abbasi, A. Shahrabadi, and H. Golghanddashti, "Experimental investigation of clay minerals' effects on the permeability reduction in water injection process in the oil fields," in SPE European Formation Damage Conference, Noordwijk, The Netherlands, 2011.

[6] N. Golsanami, E. Bakhshi, W. Yan et al., "Relationships between the geomechanical parameters and Archie's coefficients of fractured carbonate reservoirs: a new insight," Energy Sources, Part A: Recovery, Utilization, and Environmental Effects, pp. 1-25, 2020.

[7] W. Yan, J. Sun, N. Golsanami et al., "Evaluation of wettabilities and pores in tight oil reservoirs by a new experimental design," Fuel, vol. 252, pp. 272-280, 2019.

[8] D. Ma and B. Jiang, "A smooth curve as a fractal under the third definition," Cartographica, vol. 53, no. 3, pp. 203-210, 2018.

[9] Q. Meng, C. Liu, Q. Chen, and Y. Ye, "Natural gas hydrate dissociation," in Natural Gas Hydrates, Springer Geophysics, Y. Ye and C. Liu, Eds., pp. 261-283, Springer, Berlin, Heidelberg, 2013.

[10] M. I. Qadir and M. Asrar, "SPE 156516 gas hydrates: a fuel for future but wrapped in drilling challenges," in SPE/PAPG Annual Technical Conference, Islamabad, Pakistan, 2011.

[11] A. V. Palodkar and A. K. Jana, "Gas hydrate dynamics in distributed porous particles with saltwater: model formulation and experimental validation," Chemical Engineering Journal, vol. 392, article 123660, 2020.

[12] K. Malekani, J. A. Rice, and J. Lin, "Comparison of techniques for determining the fractal dimensions of clay minerals," Clays and Clay Minerals, vol. 44, no. 5, pp. 677-685, 1996.

[13] Y. Xu and X. Xia, "Fractal model for virgin compression of pure clays," Mechanics Research Communications, vol. 33, no. 2, pp. 206-216, 2006.

[14] M. I. Ozhovan, I. E. Dmitriev, and O. G. Batyukhnova, "Fractal structure of pores in clay soil," Atomic Energy, vol. 74, no. 3, pp. 241-243, 1993.

[15] K. Chen, H. Chen, and P. Xu, "A new relative permeability model of unsaturated porous media based on fractal theory," Fractals, vol. 28, no. 1, article 2050002, 2020.

[16] S. Dong, L. Xu, Z. Dai et al., "A novel fractal model for estimating permeability in low-permeable sandstone reservoirs," Fractals, vol. 28, no. 8, article 2040005, 2020.

[17] R. Li, Z. Chen, K. Wu et al., "A fractal model for gas-water relative permeability curve in shale rocks," Journal of Natural Gas Science and Engineering, vol. 81, article 103417, 2020.

[18] G. Sheng, Y. Su, and W. Wang, "A new fractal approach for describing induced-fracture porosity/permeability/compressibility in stimulated unconventional reservoirs," Journal of Petroleum Science and Engineering, vol. 179, pp. 855-866, 2019.

[19] E. Bakhshi, N. Golsanami, and L. Chen, "Numerical modeling and lattice method for characterizing hydraulic fracture propagation: a review of the numerical, experimental, and field studies," Archives of Computational Methods in Engineering, 2020.

[20] K. Zhang, J. Lai, G. Bai et al., "Comparison of fractal models using NMR and CT analysis in low permeability sand- stones," Marine and Petroleum Geology, vol. 112, article 104069, 2020.

[21] N. Golsanami, X. Zhang, W. Yan et al., "NMR-based study of the pore types' contribution to the elastic response of the reservoir rock," Energies, vol. 14, no. 5, p. 1513, 2021.

[22] N. Golsanami, J. Sun, Y. Liu et al., "Distinguishing fractures from matrix pores based on the practical application of rock physics inversion and NMR data: a case study from an unconventional coal reservoir in China," Journal of Natural Gas Science and Engineering, vol. 65, pp. 145-167, 2019.

[23] L. Jiang, Y. Zhao, N. Golsanami, L. Chen, and W. Yan, "A novel type of neural networks for feature engineering of geological data: case studies of coal and gas hydrate-bearing sediments," Geoscience Frontiers, vol. 11, no. 5, pp. 1511-1531, 2020.

[24] X. Dong, L. W. Shen, N. Golsanami et al., "How $\mathrm{N}_{2}$ injection improves the hydrocarbon recovery of $\mathrm{CO}_{2} \mathrm{HnP}$ : An NMR study on the fluid displacement mechanisms," Fuel, vol. 278, p. 118286, 2020.

[25] D. Dey, P. Müller, and D. Sinha, Practical Nonparametric and Semiparametric Bayesian Statistics, Springer, 1998.

[26] D. Huaimin, S. Jianmeng, C. Likai, G. Naser, and Y. Weichao, "Characteristics of the pore structure of natural gas hydrate reservoir in the Qilian Mountain permafrost, Northwest China," Journal of Applied Geophysics, vol. 164, pp. 153-159, 2019.

[27] H. Dong, J. Sun, N. Golsanami et al., "A method to construct high-precision complex pore digital rock," Journal of Geophysics and Engineering, vol. 15, no. 6, pp. 2695-2703, 2018.

[28] M. S. Jouini, S. Vega, and A. Al-Ratrout, "Numerical estimation of carbonate rock properties using multiscale images," Geophysical Prospecting, vol. 63, no. 2, pp. 405-421, 2015.

[29] R. S. Devarapalli, A. Islam, T. F. Faisal, M. Sassi, and M. Jouiad, "Micro-CT and FIB-SEM imaging and pore structure characterization of dolomite rock at multiple scales," Arabian Journal of Geosciences, vol. 10, no. 16, p. 361, 2017.

[30] C. Soulaine, F. Gjetvaj, C. Garing et al., "The impact of subresolution porosity of X-ray microtomography images on the permeability," Transport in Porous Media, vol. 113, no. 1, pp. 227-243, 2016.

[31] B. Huang, X. Xiao, D. Cai, R. W. T. Wilkins, and M. Liu, "Oil families and their source rocks in the Weixinan sub-basin, Beibuwan Basin, South China Sea," Organic Geochemistry, vol. 42, no. 2, pp. 134-145, 2011.

[32] B. Huang, H. Tian, R. W. T. Wilkins, X. Xiao, and L. Li, "Geochemical characteristics, palaeoenvironment and formation model of Eocene organic-rich shales in the Beibuwan Basin, South China Sea," Marine and Petroleum Geology, vol. 48, pp. 77-89, 2013.

[33] P. Li, C. Z. Di Zhou, and G. Chen, "Assessment of the effective $\mathrm{CO} 2$ storage capacity in the Beibuwan Basin, offshore of southwestern P. R. China," International Journal of Greenhouse Gas Control, vol. 37, pp. 325-339, 2015.

[34] J. He, H. Liu, Y. Yao, S. Zhang, and X. Nian, Oil and Gas Geology and Resource Potential of Northern South China Sea Marginal Basins, Petroleum Industry Press, Beijing, 2008.

[35] B. Li, Y. Sun, W. Guo et al., "The mechanism and verification analysis of permafrost-associated gas hydrate formation in the Qilian Mountain, Northwest China," Marine and Petroleum Geology, vol. 86, pp. 787-797, 2017. 
[36] C. Peng, C. Zou, Z. Lu et al., "Characteristics of gas hydrate reservoirs and their effect on petrophysical properties in the Muli area, Qinghai-Tibetan plateau permafrost," Journal of Natural Gas Science and Engineering, vol. 57, pp. 266-283, 2018.

[37] L. Qu, C. Zou, Z. Lu et al., "Elastic-wave velocity characterization of gas hydrate-bearing fractured reservoirs in a permafrost area of the Qilian Mountain, Northwest China," Marine and Petroleum Geology, vol. 88, pp. 1047-1058, 2017.

[38] C. Liu, Q. Meng, X. He et al., "Comparison of the characteristics for natural gas hydrate recovered from marine and terrestrial areas in China," International Journal of Greenhouse Gas Control, vol. 152, pp. 67-74, 2015.

[39] H. Fang, M. Xu, Z. Lin et al., "Geophysical characteristics of gas hydrate in the Muli area, Qinghai Province," Journal of Natural Gas Science and Engineering, vol. 37, pp. 539-550, 2017.

[40] B. Cheng, J. Xu, Z. Lu et al., "Hydrocarbon source for oil and gas indication associated with gas hydrate and its significance in the Qilian Mountain permafrost, Qinghai, Northwest China," Marine and Petroleum Geology, vol. 89, pp. 202-215, 2018.

[41] X. Hu, C. Zou, Z. Lu et al., "Evaluation of gas hydrate saturation by effective medium theory in shaly sands: a case study from the Qilian Mountain permafrost, China," Journal of Geophysics and Engineering, vol. 16, no. 1, pp. 215-228, 2019.

[42] S. Guggenheim, R. T. Martin, A. Alietti et al., "Definition of clay and clay mineral: joint report of the AIPEA nomenclature and CMS nomenclature committees," Clays and Clay Minerals, vol. 43, no. 2, pp. 255-256, 1995.

[43] J. M. Huggett, "Clay minerals," in Encyclopedia of Geology (Second Edition), Elsevier, 2021.

[44] B. Mandelbrot, The Fractal Geometry of Nature, 2nd Prt, Times Books, 1982.

[45] A. L. Karperien and H. F. Jelinek, "Fractal, multifractal, and lacunarity analysis of microglia in tissue engineering," Frontiers in Bioengineering and Biotechnology, vol. 3, pp. 20132016, 2015.

[46] T. G. Smith, G. D. Lange, and W. B. Marks, "Fractal methods and results in cellular morphology - dimensions, lacunarity and multifractals," Journal of Neuroscience Methods, vol. 69, no. 2, pp. 123-136, 1996.

[47] Y. Xia, J. Cai, E. Perfect, W. Wei, Q. Zhang, and Q. Meng, "Fractal dimension, lacunarity and succolarity analyses on CT images of reservoir rocks for permeability prediction," Journal of Hydrology, vol. 579, article 124198, 2019.

[48] R. H. C. De Melo and A. Conci, "Succolarity: defining a method to calculate this fractal measure," in 2008 15th International Conference on Systems, Signals and Image Processing, pp. 291-294, Bratislava, Slovakia, 2008.

[49] Y. Xia, J. Cai, and W. Wei, "Fractal structural parameters from images: fractal dimension, lacunarity, and succolarity," in Modelling of Flow and Transport in Fractal Porous Media, pp. 11-24, Elsevier, 2021.

[50] C. E. Krohn, "Sandstone fractal and Euclidean pore volume distributions," Journal of Geophysical Research, vol. 93, no. B4, pp. 3286-3296, 1988.

[51] A. J. Katz and A. H. Thompson, "Fractal sandstone pores: implications for conductivity and pore formation," Physical Review Letters, vol. 54, no. 12, pp. 1325-1328, 1985.

[52] L. Liu, S. Dai, F. Ning, J. Cai, C. Liu, and N. Wu, "Fractal characteristics of unsaturated sands - implications to relative per- meability in hydrate-bearing sediments," Journal of Natural Gas Science and Engineering, vol. 66, pp. 11-17, 2019.

[53] S. L. Li, Q. L. Ma, C. Y. Sun et al., "A fractal approach on modeling gas hydrate phase equilibria in porous media," Fluid Phase Equilibria, vol. 356, pp. 277-283, 2013.

[54] L. Liu, Z. Zhang, C. Li et al., "Hydrate growth in quartzitic sands and implication of pore fractal characteristics to hydraulic, mechanical, and electrical properties of hydrate-bearing sediments," Journal of Natural Gas Science and Engineering, vol. 75, article 103109, 2020.

[55] H. Dong, J. Sun, J. Zhu et al., "Developing a new hydrate saturation calculation model for hydrate-bearing sediments," Fuel, vol. 248, pp. 27-37, 2019.

[56] H. Dong, J. Sun, M. Arif, N. Golsanami, W. Yan, and Y. Zhang, "A novel hybrid method for gas hydrate filling modes identification via digital rock," Marine and Petroleum Geology, vol. 115, article 104255, 2020.

[57] P. Pfeifer and D. Avnir, "Chemistry in noninteger dimensions between two and three. I. Fractal theory of heterogeneous surfaces," The Journal of Chemical Physics, vol. 79, no. 7, pp. 3558-3565, 1983.

[58] Z. Zhang and A. Weller, "Fractal dimension of pore-space geometry of an Eocene sandstone formation," Geophysics, vol. 79, no. 6, pp. D377-D387, 2014.

[59] S. Zhou, D. Liu, Y. Cai, and Y. Yao, "Fractal characterization of pore-fracture in low-rank coals using a low-field NMR relaxation method," Fuel, vol. 181, pp. 218-226, 2016.

[60] P. C. Carman, "Fluid flow through granular beds," Chemical Engineering Research and Design, vol. 75, pp. S32-S48, 1997.

[61] J. Kozeny, "Über kapillare Leitung des Wassers im Boden: Sitzungsberichte der Akademie der Wissenschaften in Wien," vol. 136, pp. 271-306, 1927, March 2020, http://www.oalib .com/references/18983736.

[62] A. Ismail, Q. Yasin, and Q. Du, “Application of hydraulic flow unit for pore size distribution analysis in highly heterogeneous sandstone reservoir: a case study," Journal of the Japan Petroleum Institute, vol. 61, no. 5, pp. 246-255, 2018.

[63] A. Ismail, Q. Yasin, Q. Du, and A. Ali Bhatti, "A comparative study of empirical, statistical and virtual analysis for the estimation of pore network permeability," Journal of Natural Gas Science and Engineering, vol. 45, pp. 825-839, 2017.

[64] C. Allain and M. Cloitre, "Characterizing the lacunarity of random and deterministic fractal sets," Physical Review A, vol. 44, no. 6, pp. 3552-3558, 1991.

[65] G. Chen, G. Du, G. Zhang, Q. Wang, C. Lv, and J. Chen, "Chlorite cement and its effect on the reservoir quality of sandstones from the Panyu low-uplift, Pearl River Mouth Basin," Petroleum Science, vol. 8, no. 2, pp. 143-150, 2011. 